\title{
TO KIT OR NOT TO KIT: ANALYSING THE VALUE OF MODEL-BASED KITTING FOR ADDITIVE MANUFACTURING
}

\author{
Siavash H. Khajavi ${ }^{1}$, Martin Baumers ${ }^{2}$, Jan Holmström ${ }^{1}$, Ender Özcan ${ }^{3}$, Jason Atkin ${ }^{3}$, \\ Warren Jackson ${ }^{3}$, Wenwen $\mathbf{L i}^{3}$ \\ ${ }^{1}$ Department of Industrial Engineering and Management, Aalto University, \\ Maarintie 8, Finland \\ siavash.khajavi@aalto.fi, jan.holmstrom@aalto.fi \\ ${ }^{2}$ Faculty of Engineering, University of Nottingham, \\ NG7 2RD, Nottingham, UK \\ martin.baumers@nottingham.ac.uk \\ ${ }^{3}$ School of Computer Science, University of Nottingham, \\ NG8 1BB, Nottingham, UK \\ ender.ozcan@nottingham.ac.uk, jason.atkin@,nottingham.ac.uk, warren.jackson@,nottingham.ac.uk, \\ wenwen.li@nottingham.ac.uk
}

\begin{abstract}
The use of additive manufacturing (AM) for the production of functional parts is increasing. Thus, AM based practices that can reduce supply chain costs gain in importance. We take a forward-looking approach and study how AM can be used more effectively in the production of multi-part products in low to medium quantities. The impact of introducing kitting in AM on supply chain cost is investigated. Kitting approaches are traditionally devised to feed all components belonging to an assembly into individual containers. Where conventional manufacturing approaches are used for kitting, the produced parts pass through inventory and a kit preparation step before being forwarded to the assembly line/station. However, by taking advantage of the object-oriented information handling inherent in the AM process, kitting information can be embedded directly within the digital design data and parts produced in a common build. This model-based kitting practice reduces - even eliminates - the need for a manual kit preparation step and promises additional supply chain benefits. Eight experiments were conducted using laser sintering (LS) to investigate the impact of model-based component kitting on production cost and supply chain cost. The results show that with current state-of-the art volume packing software production costs increase with the adoption of kitting. The increased production cost, was off-set by benefits, including simplified production planning, reduced work-in-progress inventory and elimination of parts fetching prior to assembly. Findings of this research are of interest for manufacturers, service bureaus and practitioners who use AM for low quantity production, as well as developers of AM volume packing and production planning software.
\end{abstract}

\section{Keywords}

Additive manufacturing, component kitting, supply chain, cost study, capacity aggregation, packing optimisation, production planning 


\section{Introduction}

In manufacturing, the practise of kitting [6] to supply the required parts for a single assembly in pre-set containers provides an alternative to the currently dominant practice of continuous supply line-stocking. Kitting reduces operator learning requirements [25] and improves the assembly quality and efficiency $[5,6,18,19]$. Up to this point, however, kitting has not challenged continuous line-stocking as the dominant approach even in low to medium volume production. Parts are typically produced in large batches. In this setting, the preparation of kits constitutes an additional process step that requires stocking and fetching of individual parts before grouping of the components into kits. These required, often manual kitting, procedures create a range of problems, such as missing parts and incorrectly composed kits.

Additive Manufacturing (AM) represents an opportunity to produce kits directly on the basis of a design model [28]. By utilising approaches such as the composite design pattern [12], the digital design model used in producing the part can encompass additional information that defines how the parts are related, for example, as components in an assembly kit. While currently AM is only used for the production of individual functional parts in mainly aerospace and medical products, the emergence of significantly cheaper polymer laser sintering machines is likely to expand the use of AM to many - even all - parts of an assembly [<ADD HERE A REF: Holmström, J., Liotta, G., \& Chaudhuri, A. (2017). Sustainability outcomes through direct digital manufacturing-based operational practices: A design theory approach. Journal of Cleaner Production.>]. Therefore, it is important to begin investigating how the new AM enabled practice of model-based kitting impacts costs and performance in the supply chain.

One of the factors that influences the manufacturing cost of AM, and consequently its competitiveness with conventional processes, is the build volume packing. The production unit cost can be decreased by optimising the arrangement of the parts in the chamber [3]. However, in more realistic settings, such as an AM service bureau's supply chain, a number of additional elements must be considered. These elements include the order delivery schedule (which may result in stock outs or inventory carrying), the product assembly process (for multi-part, hybrid products, which may result in delivery delay and additional manual work) and durability of the produced parts (to achieve certain engineering requirements, the orientation of parts may need to be fixed). Therefore, it is important to minimize the total cost by considering the entire supply chain rather than focusing on the build volume packing in isolation. Addressing this question, this research sheds light on the value of model-based kitting in AM for the production of multi-process (AM and conventional), multi-part products. Two case-assisted investigations are conducted to illustrate the advantages and disadvantages of utilising pre-set kits in the supply chain context.

The remainder of this paper is organized as follows. Section 2 presents a literature review, Section 3 explains the research methodology, Section 4 presents the findings and results of our analysis and Section 5 is dedicated to the discussion of the results. This paper ends with conclusions summarizing the research outcomes and suggestions for future investigations.

\section{Literature review}

This section reviews the existing literature in the fields of AM and pre-set kitting.

\subsection{Additive manufacturing}

AM, also known as three-dimensional printing, is a manufacturing process that differs from conventional manufacturing in terms of its operating principle [21]. Instead of removing material to 
generate the intended shape, AM adds material layer by layer to produce objects. There are multiple AM processes which are capable of generating end-use objects and each process variant utilises one or more build materials. The range of build materials for AM is growing and currently includes various metals, metallic alloys, polymers, ceramics and composites [17].

Additive manufacturing has a number of characteristics that make it attractive for various industries $[26,27]$. The possibility of toolless production, enables the economic production of very small quantities, down to a single unit. The layer by layer nature of the process makes it possible to produce complex geometries (as well as assemblies) that are difficult to manufacture with traditional manufacturing processes [22]. This allows designers to design for performance and pay less attention to design for manufacturing [35]. Moreover, in metal AM, layer-wise production significantly reduces the amount of waste raw material as a large percentage of the unused raw material can be reused. The resulting savings can be significant when the production requires the use of valuable metals, such as titanium [14].

Polymer powder bed fusion, also known as laser sintering (LS), which is a common powder-based AM process used to produce functional polymer parts, has been used in high-value applications, such as those found in the aerospace industry (air cooling ducts on Boeing's F-18 Super Hornets and 787 commercial airliners according to Freedman, [15]). The LS process begins with a computer-aided design (CAD) file, which is created or acquired from a source. Then, the three-dimensional design is converted into .stl format and analysed using special software for additive manufacturability. This step is concerned with the object wall thickness and other problems, such as inappropriate collision of triangles, which determine the actual surfaces in the .stl format. The LS method is performed without a support structure for the overhangs as the unsintered powder acts as the support, obviating the need for software-generated support structures. The next step involves feeding the error-checked design file to the software supplied by the LS machine manufacturer, for slicing and creation of the print layers. The output of this step is a file that contains all the production layers, which can be loaded into other software for packing of the print job in the production chamber and final touches, such as shrinkage value setup. To avoid thermal shock on the parts, blank layers of powder are included during this step at the beginning and the end of the job. The output of this step is sent directly to the LS machine controller computer, upon which the operator releases the build process (for details on AM technology variants, see Gibson et al. [17] or Hopkinson et al. [23]).

It takes approximately two hours for the machine to heat the powder, prepare the chamber nitrogen atmosphere and start the production process. A laser is used to selectively sinter the pre-heated powder on each layer until all of the parts have been formed. When the LS completes the build process, the parts are placed in an oven to gradually cool. This step can take up to one day. Then, the secondary processes are started, including recovery of the parts from the powder, blasting and washing, which are highly manual tasks. After these processes, the parts are ready for assembly and delivery to customers (for the time required for the LS process steps, see Baumers et al., [3]).

When AM is used in final part production applications, the .stl file format illustrates its constraints as it is limited to contain only the components' geometrical data. Therefore, a number of new formats, such as the Additive Manufacturing File (AMF) and the 3D Manufacturing Format (3MF), which are based on the extensible markup language (XML) data format, were created. The new formats are human readable and enable the inclusion of information about the material, texture, substructures, part constellation, surface mesh and colour. Moreover, these formats are designed to be able to adapt to future needs, meaning that they can be extended to incorporate additional required data [29]. This potentially opens the door for integration of AM into companies' ERP systems and supply chains while streamlining the production process.

\subsubsection{Capacity utilisation in LS}


Research on the relationship between cost efficiency and capacity utilisation in AM $[4,33]$ has shown that the build configuration affects the observed unit cost, which is addressable by automated build volume packing approaches [1]. The degree of capacity utilisation in AM execution is determined during two steps in the process flow, machine setup and production planning. Therefore, cost efficiency and capacity utilisation in AM depend on both the build configuration and the production schedule, resulting in a connected optimisation problem. Coordinating and controlling the elements of the process through integrated optimisation requires control of how decisions are made and how competing aspects are weighed [7]. With full information and without disturbances, such as technical failures or unforeseen demand fluctuations, centralized control structures outperform decentralized structures with autonomous decision making [36].

\subsection{Pre-set kitting supply}

Kitting, as an established practise in assembly industries (such as electronics), refers to the supply of all the required components for a single assembly object in pre-set containers [6]. Kits can be used in stationary or assembly line settings. The practise of pre-set kitting supply is in contrast to line-stocking in-plant supply, which presents each stock keeping unit (SKU) in bulk in containers (or boxes) along the assembly line [18]. This significant difference has been studied in various industries and has been illustrated to have the following benefits and shortcomings for kitting supply (Table 1).

Table 1: Comparison between line-stocking and pre-set kitting line feeding modes

Line-stocking

\begin{tabular}{|c|c|c|}
\hline Advantages & - Lower operating cost [20] & $\begin{array}{l}\text { - Improvement in assembly operator } \\
\text { working conditions [24] } \\
\text { - Saves space at the border of the } \\
\text { production line }[24,11] \\
\text { - } \\
\text { Appropriate for high product variety } \\
\text { - } 24] \\
\text { Can be used in stationary or } \\
\text { travelling modes [34] } \\
\text { - Minimization of work-in-progress } \\
\text { - } \quad \text { Reduced assembler learning times } \\
\quad[25] \\
\text { - Long cycle times provide a holistic } \\
\text { view and meaning to assemblers' } \\
\text { tasks [31, 10] } \\
\text { In parallel production setting, line } \\
\text { balancing problem does not exist } \\
{[16]}\end{array}$ \\
\hline Disadvantages & $\begin{array}{ll}\text { - } & \text { Appropriate for low product } \\
& \text { variety [37] } \\
\text { - } & \text { Space intensive [24, 38] } \\
\text { - } & \text { Time-consuming parts fetching } \\
& \text { on the line [24] } \\
\text { - } & \begin{array}{l}\text { Psychosocial impact of } \\
\text { repetitive tasks and short cycle } \\
\text { time [11] }\end{array}\end{array}$ & $\begin{array}{l}\text { Requires an additional preparation } \\
\text { step before assembly operation } \\
\text { (order picking), which requires } \\
\text { additional space and labour }[18,20]\end{array}$ \\
\hline
\end{tabular}

The main benefits of kitting over line-stocking according to the literature are improving working conditions of assembly workers [24], reducing the workers learning time [25], and providing a more holistic view of the assembly task [10,31]. Moreover, the elimination of line balancing when kitting 
enables parallel work [16], and a reduced need for stocking locations along the production line [11, 24] are further benefits of kitting compared to line-stocking. On the other hand, compared to line-stocking literature points out the higher cost of operation when manual kit preparation steps are required [18, $20]$.

Among the most controversial utilisations of kitting to replace line-stocking is the example of the Volvo Uddevalla plant [11]. The Volvo's reflective production system at the Uddevalla plant resulted in better working conditions and higher employee satisfaction [30,9]. Never the less, the plant was closed after just over a year in operation [31]. The plant closure was due to the labour intensiveness of the kit preparation process, as well as market shrinkage for Volvo and macroeconomic changes [31]. In the Uddevalla plant more than 10 per cent of the employees were responsible for picking parts and preparing the kits for the assembly teams. Moreover, Volvo found a 20 per cent productivity disadvantage for the kitting line feeding mode compared to the line-stocking mode [31]. Therefore, due to the labour intensiveness of its preparation steps, kitting had a lower level of overall efficiency, although it offered higher product quality $[25,20]$.

It is clear in the literature that, if the preparation steps are ignored, kitting offers higher performance in the reduction of space requirements, work-in-progress and flow of containers compared to line-stocking mode $[6,20]$. However, elimination of the kit preparation step is not feasible with conventional manufacturing methods.

\subsection{Gap in the literature}

The literature suggests that the pre-set kitting line feed mode is more expensive to operate than linestocking due to its labour-intensive preparation steps. Moreover, the lower storage requirements on the production line and the lower time and energy expenditures to pick the parts during assembly are the areas of strength for pre-set kitting [34]. However, additive manufacturing, in contrast to conventional manufacturing, which produces high volumes of a single SKU at a time, can make a variety of different parts during each run $[33,32]$. Therefore, the labour-intensive kit preparation step (manual task of fetching parts and readying kits before feeding to the production line) can be fully avoided, since the kit information can be embedded into the product 3D design file. Used in conjunction with AM, this aspect can generate significant benefits from kitting while avoiding its main drawback. However, to fully understand this novel concept in AM and its usefulness, we need to investigate the effect of AM build volume utilisation as a major factor in the total cost. In other words, the relationships between the build volume packing and scheduling problem and the kitting approach need to be assessed to determine whether the advantages of kitting outweigh any efficiency losses from the configurations no longer being free. Previous research by Lyly-Yrjänäinen et al., [28] suggested the possibility of kitting utilisation for parts production in AM; however, it falls short of empirical assessment through the use of AM-based direct digital manufacturing methods. The aim of this research is therefore to illustrate the benefits of associating data regarding the kitting of parts with the 3D design files and to empirically analyse the cost and benefits of producing and supplying kitted parts to the production line in the supply chain setting.

Previous studies have emphasized the scarcity of quantitative research on the benefits and shortcomings of the kitting line feeding mode [34]. In this research, we thus investigate kitting combined with the novel production method of AM, from a cost perspective, for in-house production, while also performing a qualitative analysis of the supply chain implications. In doing so, we aim to answer the following research questions:

RQ1: What is the cost of utilising kitting in additive manufacturing from a production perspective?

RQ2: What are the costs and benefits of a pre-set kitting scheme for AM in a supply chain setting? 
RQ3: Does the production-level cost impact of adopting kitting in AM (RQ1) outweigh the supply chain-level benefits of adopting a kitting scheme (RQ2)?

\section{Research methodology}

This research uses a forward-looking approach to study an improvement opportunity that is only emerging as AM is more widely used to produce functional parts for products in low to medium quantities. The hypothesis of this research is that model-based kitting becomes potentially useful when $\mathrm{AM}$, and more specifically laser sintering, is introduces for the production of functional parts of multipart products in low to medium quantities. In the following section research methodology overview is presented.

\subsection{Overview of the method}

An overview of the research process is presented in Figure 1 and is described in this section.

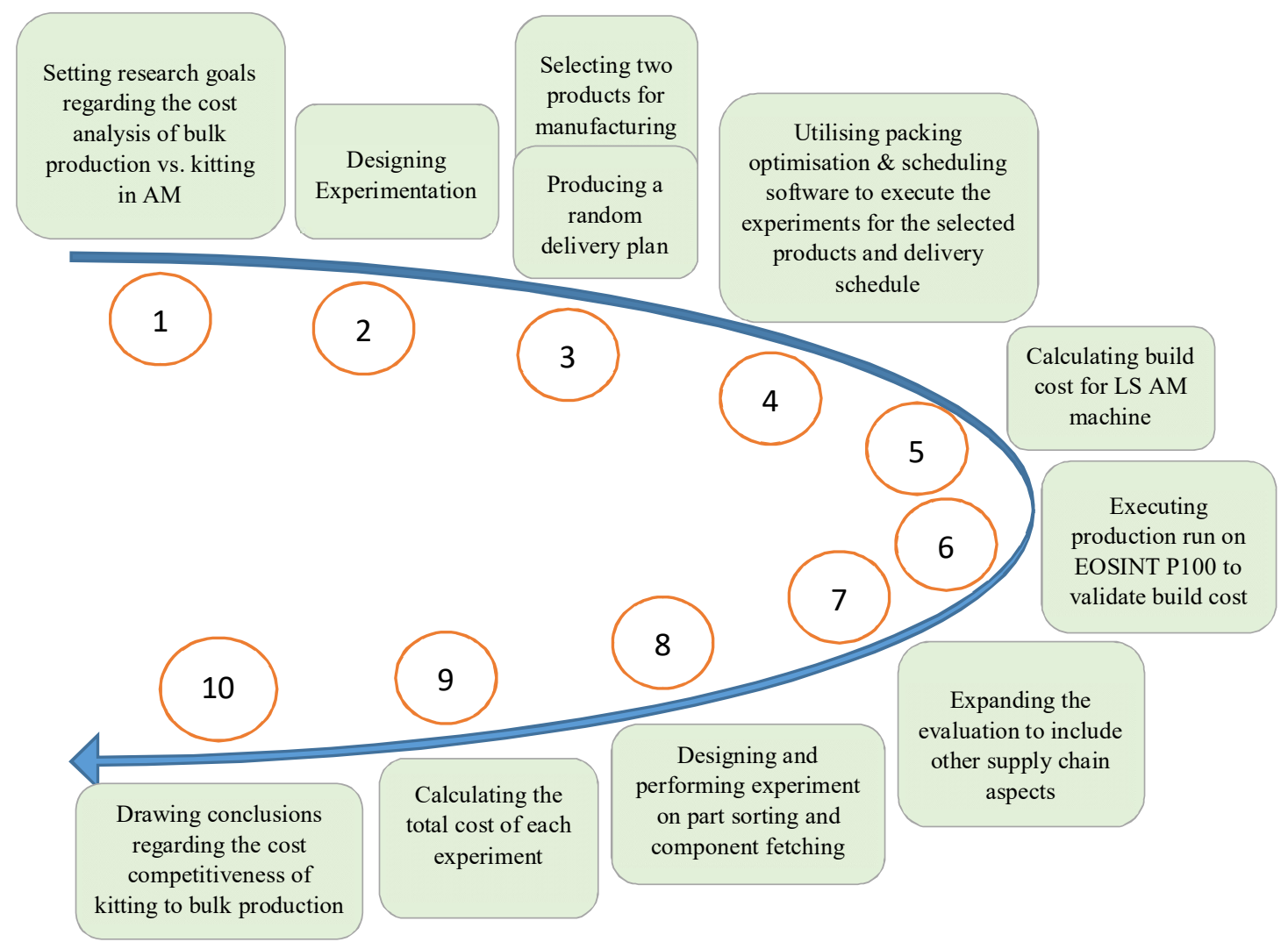

Figure 1: Research process

\subsection{Experimentation design}

The research approach is based on repeatedly executing a computational workflow optimisation tool to test for the cost effect of different permutations of problem features and constraints. Overall, there are eight executions, which correspond to eight experiments that are designed to compare the impact of kitting parts for AM with bulk printing of the parts for the LS. Two constraints, i.e., delivery priority and engineering requirements, are considered. Our experimental methodology is specified such that all AM production runs are performed while the machine chamber is packed with the parts in an optimised 
manner. To satisfy this assumption, a home-grown software system, which is designed to generate optimised AM workflows, is utilised (3DPackRAT). The system has been developed and implemented at the University of Nottingham.

This software (3DPackRAT) although is a cutting-edge system for production chamber packing optimization, it still does not accommodate the kit recognition. As a result, when multiple parts are loaded to the software in a single .stl file, the system treats it as a single unit and does not perform optimization inside the unit. This results in significant losses of packing efficiency when loading multiple kits into a chamber due to a lack of optimization in the cuboids surrounding the parts in the kits. Treating the parts of a kit as a single unit removes the capability of the software to optimize each cuboid internally based on its position in relation to cuboids of other kits in the chamber. Recognizing this limitation in the current chamber packing software we proceed to investigate the model-based kitting practice in a set of experiments. For more information on the chamber packing software refer to Baumers et al. [2].

Table 2: Differences between the eight AM experiments

\begin{tabular}{|c|c|c|c|c|c|c|c|c|c|}
\hline & Data & $\begin{array}{c}\text { Experime } \\
\text { nt } 1\end{array}$ & $\begin{array}{c}\text { Experime } \\
\text { nt } 2 \\
\end{array}$ & $\begin{array}{c}\text { Experime } \\
\text { nt } 3 \\
\end{array}$ & $\begin{array}{c}\text { Experime } \\
\text { nt } 4\end{array}$ & $\begin{array}{c}\text { Experime } \\
\text { nt } 5 \\
\end{array}$ & $\begin{array}{c}\text { Experime } \\
\text { nt } 6 \\
\end{array}$ & $\begin{array}{c}\text { Experime } \\
\text { nt } 7 \\
\end{array}$ & $\begin{array}{c}\text { Experime } \\
\text { nt } 8\end{array}$ \\
\hline $\begin{array}{l}\text { Base } \\
\text { condition }\end{array}$ & $\begin{array}{l}\text { Computation } \\
\text { al build } \\
\text { volume } \\
\text { packing } \\
\text { optimisation } \\
\text { of parts or } \\
\text { kits }\end{array}$ & Yes & Yes & Yes & Yes & Yes & Yes & Yes & Yes \\
\hline Feature & $\begin{array}{l}\text { Pre-set } \\
\text { kitting }\end{array}$ & No & No & Yes & Yes & No & No & Yes & Yes \\
\hline Constraint 1 & $\begin{array}{l}\text { Delivery } \\
\text { priority } \\
\text { (scheduling) }\end{array}$ & No & No & No & No & Yes & Yes & Yes & Yes \\
\hline Constraint 2 & $\begin{array}{l}\text { Engineering } \\
\text { requirements } \\
\text { (orientation) }\end{array}$ & No & Yes & No & Yes & No & Yes & No & Yes \\
\hline
\end{tabular}

As Table 2 illustrates, in Experiment 1 the parts are loaded in bulk into the available AM build space, using the build volume optimisation software. Experiment 1 does not consider any additional production constraints in the build cost analysis. Experiment 2 is slightly different from Experiment 1, as the engineering requirements constraint affects the parts' orientation and consequently the production chamber packing outcome. In all eight experiments, the production parts are packed into the AM production chamber using volume optimisation software. Experiment 3 resembles Experiment 1, with the only major difference being that the parts are loaded into the production chamber using packing optimisation software in pre-set kits. Similarly, Experiment 4 resembles Experiment 2, with the only difference being the utilisation of pre-set kits as the loading units.

Experiment 5 represents the LS additive manufacturing of parts according to a delivery schedule and with the parts loaded using chamber volume optimisation software in bulk without any other constraints. Experiment 6 is similar to Experiment 5, with the exception that Experiment 6 also considers the engineering constraints for the production parts. Experiment 7 only differs from Experiment 5 with respect to the loading manner, as it utilises pre-set kits instead of bulk loading of individual parts. Similarly, Experiment 8 differs from Experiment 6 only with respect to the loading manner as it utilises pre-set kits. For more information regarding the build flow in each experiment, refer to Appendix C.

\subsection{Manufacturing products}


A manufacturing case is created for two multi-part products (that also contain conventionally produced parts, such as fixtures and other standard components) to be produced on an LS AM machine to meet a random delivery schedule (Figure 2). Product $A$ is a drone that consists of 5 distinct parts, 4 of which are assumed to have orientation constraints (all of the parts except the camera mount). Product B is an extruder mount for a fused deposition modelling 3D printer that consists of 26 distinct parts, 9 of which are assumed to have orientation constraints (all of the gears and washers, in addition to the left and right fan ducts).
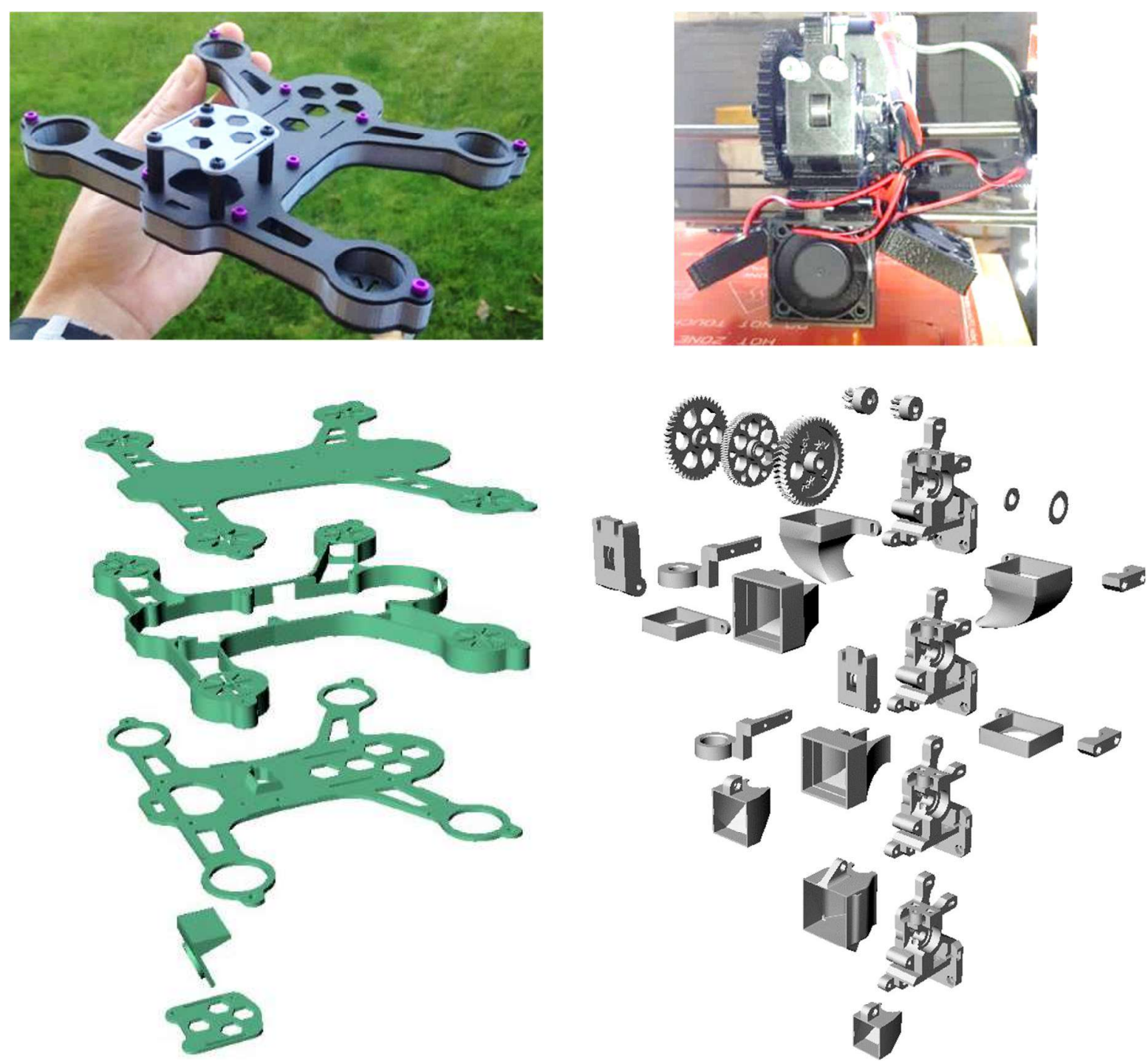

Product A

Product B

Figure 2: The products selected for the AM production plan and their explosion design rendering

Moreover, a random delivery priority schedule for a production week is created for Product A and B (Appendix A). The same priority schedule is utilised in the supply chain assessment of all the experiments because the purpose of all experiments is to meet the customer demand.

3.4. Additive manufacturing build cost model 
To answer the first research question with regard to the impact of kitting utilisation on production cost, this paper utilises the AM cost model developed by Baumers et al. [4]. To calibrate the model to accurately reflect the costs in this setting, all experiments are based on an EOSINT P100 laser sintering system at factory settings processing with nylon 12-type material. The AM build cost model takes into account the time-consuming activities on the AM machine to accurately estimate the production cost for all the experiments. The activities that are important in our cost model include the pre- and postproduction steps, such as cleaning, material loading, preparation, and warm-up, in addition to the automatic build process activities, such as powder recoating, heating and laser scanning. In this build cost model, items related to the material costs are ignored due to their lack of impact on the comparison because the parts being produced do not differ with respect to size (i.e., the amount of material used) but only by the manner in which they are packed for production.

$C_{\text {build }}=$

(pre-production heating time + post-production cleaning and preparation time) * hourly cost of AM machine + (time for powder recoating and layer heating + time required by laser to scan the whole print area * average percentage of surface fullness of each layer for the job) * number of layers * hourly cost of AM machine + hourly labour cost * (time required to perform pre-and post-production tasks)

where

average percentage of surface fullness for each layer = volume of parts in the printer chamber / total volume of the chamber up to the maximum z-height of the specific print job

and

Time required for pre- and post-production tasks for bulk loading = loading of the individual parts into the packing optimisation software and uploading the resulting stl file to the printer

while

Time required for pre- and post-production tasks for kit loading = preparation of each kit for unidentical products using the packing optimisation software + loading of the kits in the chamber using packing optimisation software and uploading of the resulting stl file to the printer

Since the cleaning of the parts after the print job is similar for all cases due to the similar total number of parts printed, we ignore this cost in our model.

For more details refer to Appendix B.

\subsection{Validation of the AM build cost model}

To validate the results generated by the build cost model, a validation experiment was performed for Experiment 7's second build job (Experiment 7 consists of five sequential builds on the AM machine) (Figure 3). This test build enabled the development of the supply chain aspect of this study by providing empirical data addressing the handling of the produced parts. 

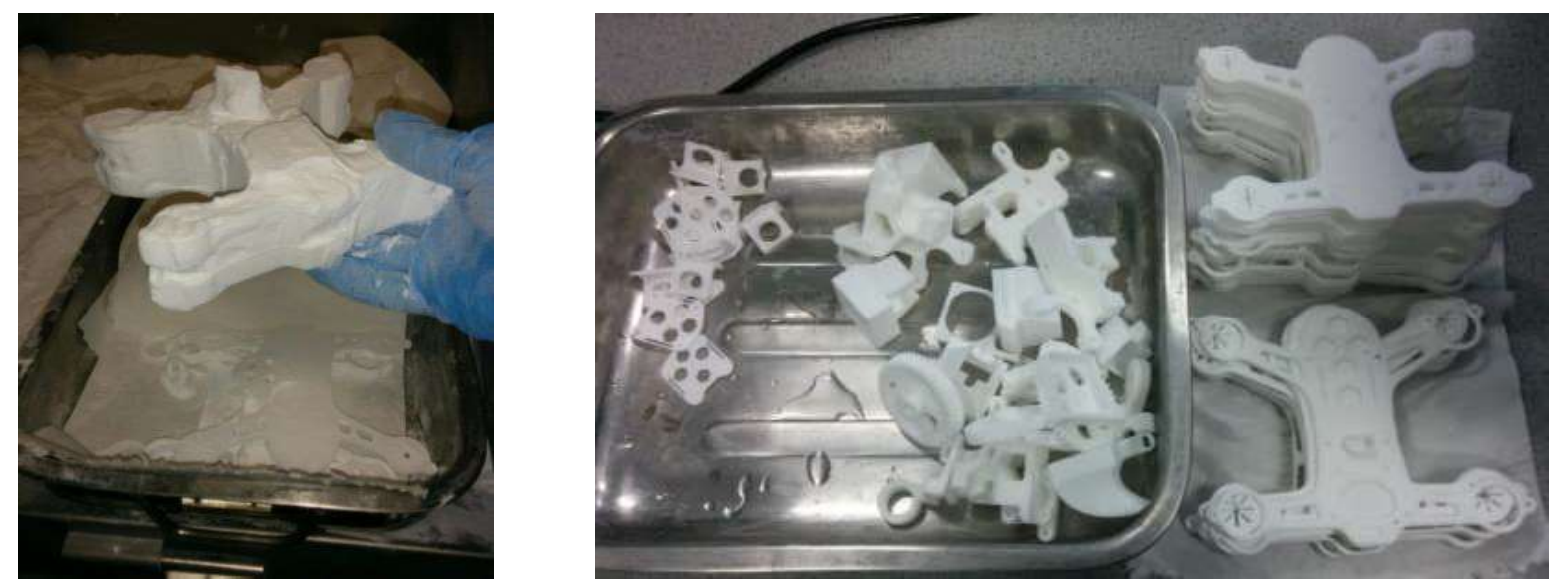

Figure 3: Kits during and after the secondary processes

3.6. Supply chain cost model development

To answer the second research question with regard to the cost-benefit analysis of kitting in additive manufacturing for supply chain operations, we performed a qualitative and quantitative analysis. Existing literature, in conjunction with our AM production test run (which set the stage for an SKU sorting and fetching experiment), is utilised to shed light on the implications of kitting for a simple make-to-order AM supply chain (Figure 4). The arrows in Figure 4 represent the transfer of information (orders or designs), raw material and goods between the supply chain participants. Moreover, the temporary storages might or might not exist depending on the type of supply chain operations.

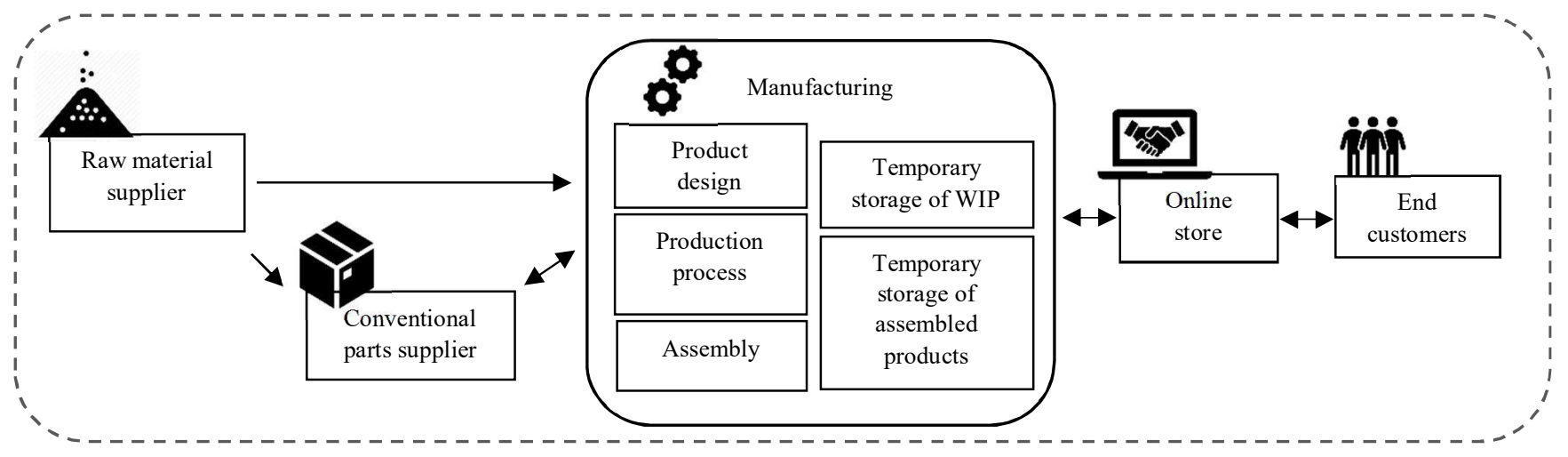

Figure 4: A generic make-to-order supply chain separated from exogenous factors

The important aspects of the supply chain that we analysed for kitting impact are as follows:

- Inventory (work-in-progress and carrying cost),

- Assembly feed operations,

- Production planning and order management.

These factors are the differentiating elements between bulk loading and kit loading in AM.

\subsection{Supply chain cost estimation experiment}

The additional cost of bulk loading compared to kit loading in a downstream supply chain is a result of the existence of work-in-progress and labour required to separate the components into different SKUs and to later fetch those parts to prepare the kits for assembly when all the required parts are ready. To gain a better view of the SKU sorting and the kit preparation activities, we performed a simple trial where an operator was ordered to separate four sets of parts (a mix of four drone and four extruder 
components) and then make three kits for each product (Figure 5). The time to perform this activity was recorded for use in the assembly feed task cost estimation (Table 3).

Table 3: The additional supply chain effort needed for bulk loading

Product A (Drone)

Product B (Extruder)

\begin{tabular}{lcc}
\hline $\begin{array}{l}\text { Sorting SKUs after printing (four } \\
\text { component sets) (seconds) }\end{array}$ & 135 & 582 \\
\hline $\begin{array}{l}\text { Fetching parts to prepare three kits } \\
\text { (seconds) }\end{array}$ & 56 & 235
\end{tabular}

It took 2 minutes and 15 seconds to find and stack all four sets of the drone product (five parts each) and 9 minutes and 42 seconds for the same operation for the four FDM extruder product sets (each consisting of 26 parts). Moreover, when preparing the kits using the SKU number and the product part lists, it took only 56 seconds for the operator to prepare the three drone kits and 3 minutes and 55 seconds for the FDM extruder kits.

These results illustrate the impact of a larger number of components on the cost of SKU separation and kit assembly. It took approximately 4.3 times longer to separate the extruder parts than it took to separate the drone parts and approximately 4.2 times longer to prepare the extruder kits than to compose the drone kits. However, it did not take more than 5 times longer, which is the ratio of the number of FDM extruder parts to the number of drone parts (26 to 5). One of the reasons for this deviation is that in the 52 compartments of the shelf, the FDM extruder parts (due to their large quantity) were arranged nearly in sequence so that the operator could spend less time searching for the right compartment while loading or fetching parts. In contrast, for the drone (which only has 5 components), the parts were scattered across various rows and columns so that the operator had to spend more time locating the right compartment. Therefore, as the number of overall SKUs increases, the amount of time required to prepare the kits increases; although the growth rates are dissimilar.

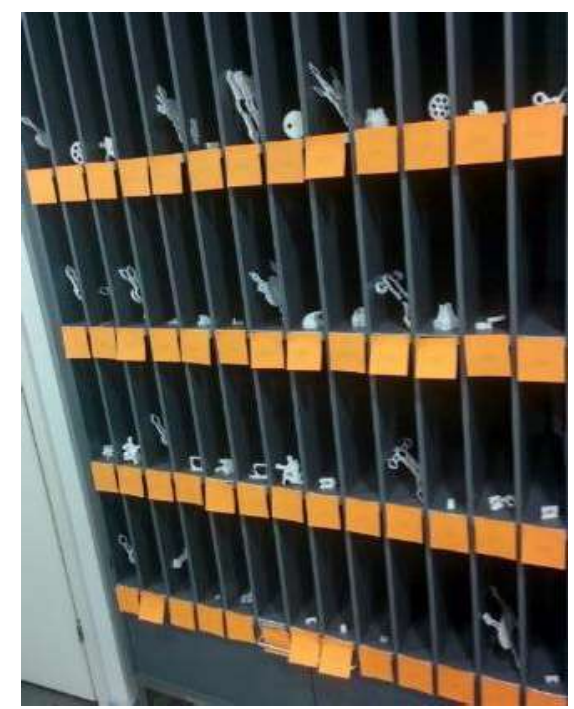

Figure 5a: Components shelf with 52 compartments

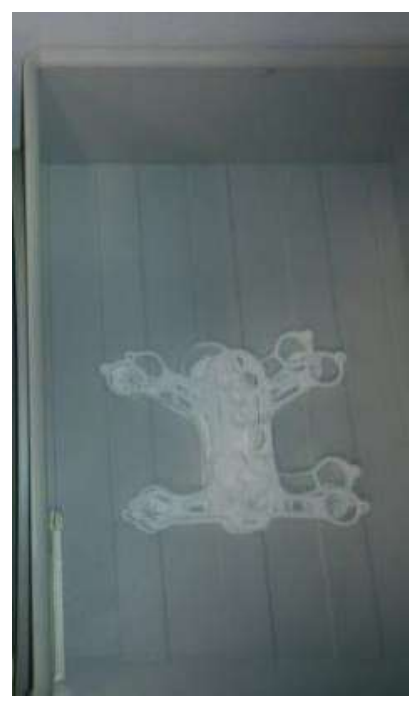

5b: A drone kit with 5 parts

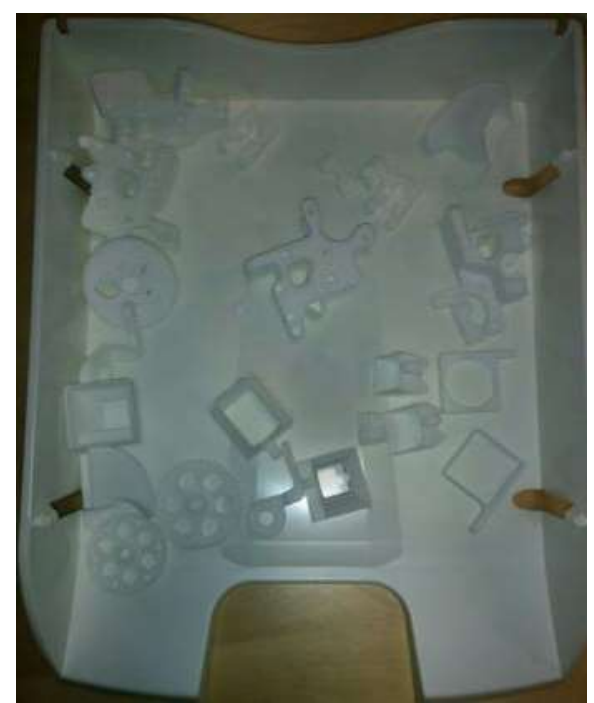

5c: An FDM extruder kit with 26 components 


\subsection{Total cost model}

Figure $6 \mathrm{a}$ and $\mathrm{b}$ illustrate the build steps and downstream supply chain steps and shows the similarities and differences in the cost models. In this analysis, we calculated and summed the dissimilar aspects of the cost models in each experiment and ignored the similar aspects (such as the material cost in the build process and the assembly activity in the supply chain) to facilitate the comparison between bulk and kit loading in additive manufacturing.

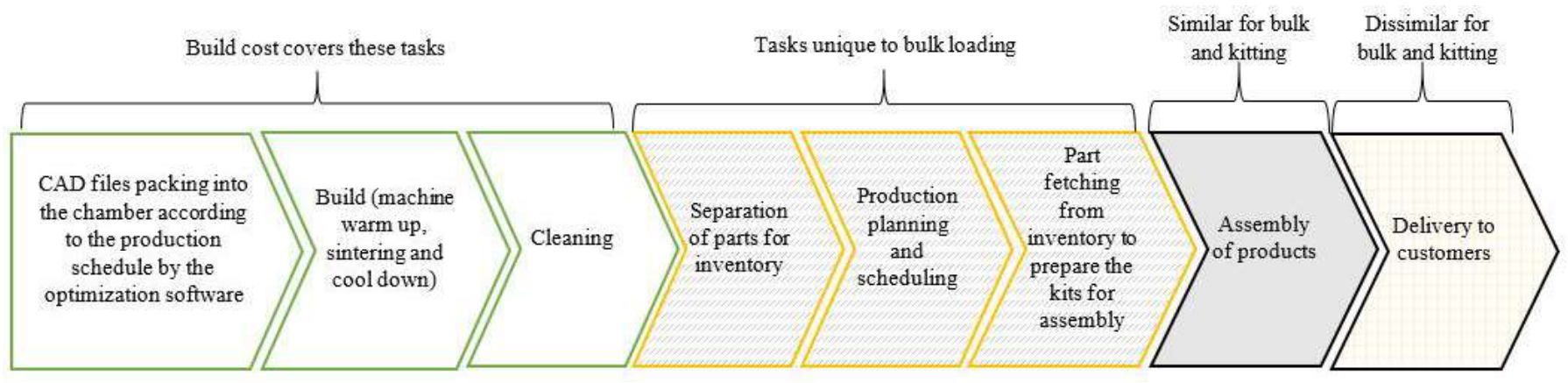

Figure 6a: AM bulk loading build and downstream supply chain tasks

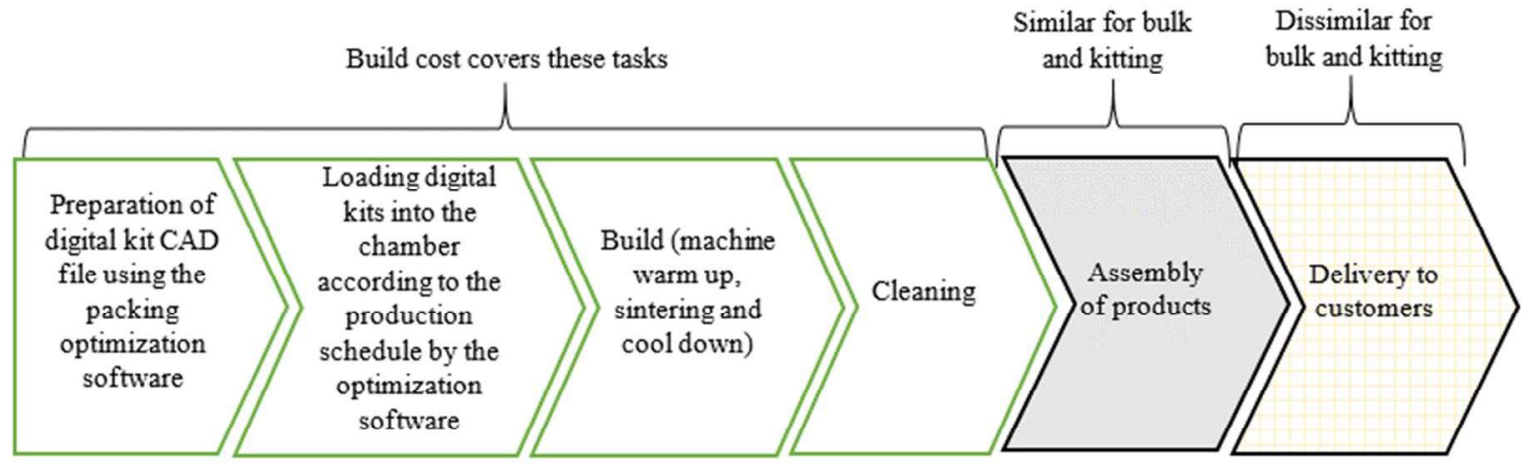

Figure 6b: AM kit mode loading build and downstream supply chain tasks

In the following sections, we present the outcomes of our analysis and the conclusions based on the cost comparison. 


\section{Results}

The results of the AM build cost and supply chain analysis are presented in Table 4 (for more details, refer to Appendix D). The build cost of the parts in the kits is higher than that of bulk production due to the superior packing optimisation results when the parts are loaded in bulk and when there are no constraints with regard to delivery schedule or orientation (engineering or cosmetic requirements). However, when the supply chain costs of bulk loading are considered, the cost gap between bulk and kitting narrows, and in Experiment 7, kit loading becomes slightly cheaper to perform.

Table 4: Additive manufacturing build cost and supply chain analysis for eight experiments

\begin{tabular}{|c|c|c|c|c|c|c|c|c|}
\hline & $\begin{array}{c}\text { Experiment } \\
1\end{array}$ & $\begin{array}{c}\text { Experiment } \\
3\end{array}$ & $\begin{array}{c}\text { Experiment } \\
2\end{array}$ & $\begin{array}{c}\text { Experiment } \\
4\end{array}$ & $\begin{array}{l}\text { Experiment } \\
5\end{array}$ & $\begin{array}{c}\text { Experiment } \\
7\end{array}$ & $\begin{array}{c}\text { Experiment } \\
6\end{array}$ & $\begin{array}{c}\text { Experiment } \\
8\end{array}$ \\
\hline $\begin{array}{l}\text { Experiment } \\
\text { description }\end{array}$ & $\begin{array}{c}\text { Bulk } \\
\text { loading of } \\
\text { the } \\
\text { assembly } \\
\text { without } \\
\text { taking into } \\
\text { account the } \\
\text { delivery and } \\
\text { engineering } \\
\text { constraints }\end{array}$ & $\begin{array}{l}\text { Kit loading } \\
\text { of the } \\
\text { assembly } \\
\text { without } \\
\text { taking into } \\
\text { account the } \\
\text { delivery and } \\
\text { engineering } \\
\text { constraints }\end{array}$ & $\begin{array}{c}\text { Bulk } \\
\text { loading of } \\
\text { the } \\
\text { assembly } \\
\text { without the } \\
\text { delivery } \\
\text { schedule but } \\
\text { with } \\
\text { engineering } \\
\text { constraints }\end{array}$ & $\begin{array}{l}\text { Kit loading } \\
\text { of the } \\
\text { assembly } \\
\text { without the } \\
\text { delivery } \\
\text { schedule but } \\
\text { with } \\
\text { engineering } \\
\text { constraints }\end{array}$ & $\begin{array}{c}\text { Bulk } \\
\text { loading of } \\
\text { the } \\
\text { assembly } \\
\text { with the } \\
\text { delivery } \\
\text { schedule but } \\
\text { without } \\
\text { engineering } \\
\text { constraints }\end{array}$ & $\begin{array}{l}\text { Kit loading } \\
\text { of the } \\
\text { assembly } \\
\text { with the } \\
\text { delivery } \\
\text { schedule but } \\
\text { without } \\
\text { engineering } \\
\text { constraints }\end{array}$ & $\begin{array}{c}\text { Bulk } \\
\text { loading of } \\
\text { the } \\
\text { assembly } \\
\text { without the } \\
\text { delivery } \\
\text { schedule } \\
\text { and } \\
\text { engineering } \\
\text { constraints }\end{array}$ & $\begin{array}{l}\text { Kit loading } \\
\text { of the } \\
\text { assembly } \\
\text { without the } \\
\text { delivery } \\
\text { schedule } \\
\text { and } \\
\text { engineering } \\
\text { constraints }\end{array}$ \\
\hline $\begin{array}{l}\text { Build Cost } \\
* \text { (total } \\
\text { demand) } \\
\end{array}$ & $\$ 512.7$ & $\$ 594.5$ & $\$ 515.1$ & $\$ 645.6$ & $\$ 605.1$ & $\$ 631.2$ & $\$ 613$ & $\$ 674.7$ \\
\hline $\begin{array}{l}\text { Number of } \\
\text { consecutive } \\
\text { builds on the } \\
\text { LS AM } \\
\text { machine }\end{array}$ & 3 & 4 & 3 & 4 & 5 & 5 & 5 & 5 \\
\hline $\begin{array}{l}\text { Time to first } \\
\text { delivery }\end{array}$ & $\begin{array}{c}\text { End of } 2^{\text {nd }} \\
\text { chamber } \\
\text { production } \\
\& \\
\text { subsequent } \\
\text { parts } \\
\text { recovery, } \\
\text { fetching \& } \\
\text { assembly }\end{array}$ & $\begin{array}{c}\text { End of } 1^{\text {st }} \\
\text { chamber } \\
\text { production } \\
\& \\
\text { subsequent } \\
\text { parts } \\
\text { recovery \& } \\
\text { assembly }\end{array}$ & $\begin{array}{c}\text { End of } 2^{\text {nd }} \\
\text { chamber } \\
\text { production } \\
\& \\
\text { subsequent } \\
\text { parts } \\
\text { recovery, } \\
\text { fetching \& } \\
\text { assembly }\end{array}$ & $\begin{array}{c}\text { End of } 1^{\text {st }} \\
\text { chamber } \\
\text { production } \\
\& \\
\text { subsequent } \\
\text { parts } \\
\text { recovery \& } \\
\text { assembly }\end{array}$ & $\begin{array}{c}\text { End of } 1^{\text {st }} \\
\text { chamber } \\
\text { production } \\
\& \\
\text { subsequent } \\
\text { parts } \\
\text { recovery, } \\
\text { fetching \& } \\
\text { assembly }\end{array}$ & $\begin{array}{c}\text { End of } 1^{\text {st }} \\
\text { chamber } \\
\text { production } \\
\& \\
\text { subsequent } \\
\text { parts } \\
\text { recovery \& } \\
\text { assembly }\end{array}$ & $\begin{array}{c}\text { End of } 1^{\text {st }} \\
\text { chamber } \\
\text { production } \\
\& \\
\text { subsequent } \\
\text { parts } \\
\text { recovery, } \\
\text { fetching \& } \\
\text { assembly }\end{array}$ & $\begin{array}{c}\text { End of } 1^{\text {st }} \\
\text { chamber } \\
\text { production } \\
\& \\
\text { subsequent } \\
\text { parts } \\
\text { recovery \& } \\
\text { assembly }\end{array}$ \\
\hline $\begin{array}{l}\text { Inventory } \\
\text { units carried } \\
\text { and for how } \\
\text { many } \\
\text { production } \\
\text { periods }\end{array}$ & $\begin{array}{l}189 \text { parts } \\
\text { for one } \\
\text { period and } \\
31 \text { parts } \\
\text { for two } \\
\text { periods }\end{array}$ & $\begin{array}{l}\text { Zero units } \\
\text { due to the } \\
\text { possibility } \\
\text { of early } \\
\text { delivery }\end{array}$ & $\begin{array}{l}77 \text { parts } \\
\text { for one } \\
\text { period and } \\
105 \text { parts } \\
\text { for two } \\
\text { periods }\end{array}$ & $\begin{array}{l}\text { Zero units } \\
\text { due to the } \\
\text { possibility } \\
\text { of early } \\
\text { delivery }\end{array}$ & $\begin{array}{l}47 \text { parts } \\
\text { for one } \\
\text { period, } 6 \\
\text { parts for } \\
\text { two } \\
\text { periods \& } \\
1 \text { part for } \\
\text { three } \\
\text { periods }\end{array}$ & $\begin{array}{l}\text { Zero units } \\
\text { due to the } \\
\text { possibility } \\
\text { of early } \\
\text { delivery }\end{array}$ & $\begin{array}{l}27 \text { parts } \\
\text { for one } \\
\text { period and } \\
10 \text { parts } \\
\text { for two } \\
\text { periods }\end{array}$ & $\begin{array}{c}\text { Zero units } \\
\text { due to the } \\
\text { possibility } \\
\text { of early } \\
\text { delivery }\end{array}$ \\
\hline $\begin{array}{l}\text { Additional } \\
\text { supply chain } \\
\text { cost of bulk } \\
\text { loading }\end{array}$ & $\$ 35.3$ & - & $\$ 35.8$ & - & $\$ 32.7$ & - & $\$ 32.5$ & - \\
\hline $\begin{array}{l}\text { Transportation } \\
\text { cost }\end{array}$ & $\$ 40$ & $\$ 45$ & $\$ 40$ & $\$ 40$ & $\$ 40$ & $\$ 45$ & $\$ 40$ & $\$ 45$ \\
\hline Total cost & $\$ 588$ & $\$ 639.5$ & $\$ 590.9$ & $\$ 685.6$ & $\$ 677.8$ & $\$ 676.2$ & $\$ 685.6$ & $\$ 719.7$ \\
\hline
\end{tabular}

*Build cost takes into account the machine-related costs and labour costs in each experiment while ignoring the material cost and post-production cleaning costs (which are the same in all experiments). Additionally, the average hourly salary of a worker (and a technician) is assumed to be \$25. The assumption with regard to part loading into the optimisation software is that it takes 5 seconds to load each part when the number of parts is less than 30 and 7 seconds on average for more than 30 parts (software lag due to complexity).

To clearly explain the research outcomes, we analyse the comparable experiments' build cost results in parallel with the supply chain aspects. 
As presented in Table 4, the build cost of Experiment 1 is approximately $31.6 \%$ lower than that of Experiment 8, which is the most expensive kitting experiment that also meets all of the constraints. The difference is only $15.9 \%$ when the build cost of Experiment 1 is compared to its kitted counterpart (Experiment 3). The production cost difference between Experiments 2 and 4 is wider than that between Experiments 1 and 3 . The $25.3 \%$ cost difference is a result of the magnified weakness in the chamber volume optimisation (due to the kitting being further constrained by the engineering requirements).

According to Table 4, Experiments 1 and 3 (similar to 2 and 4) only differ on the basis of bulk or kitted loading. This causes one additional LS AM machine run to be required to complete the production of parts for Experiment 3 (all the parts fit in three machine chambers for Experiment 1, while the kitted parts need four AM machine chambers). However, this more efficient packing for Experiment 1 comes at a price. The improved packing fills the voids with any part that fits, so parts from different assemblies are mixed together, which results in increased work-in-progress and inventory, since products are not ready for assembly until the second production run is completed due to the lack of some types of components. Production using kits does not have this disadvantage. Moreover, during the assembly of each product, the kitted experiment does not include parts sorting and fetching (Figures 7 and 8). As Figure 7 illustrates, kitting in LS additive manufacturing allows for more parallel performance of tasks, which makes it more time efficient overall.

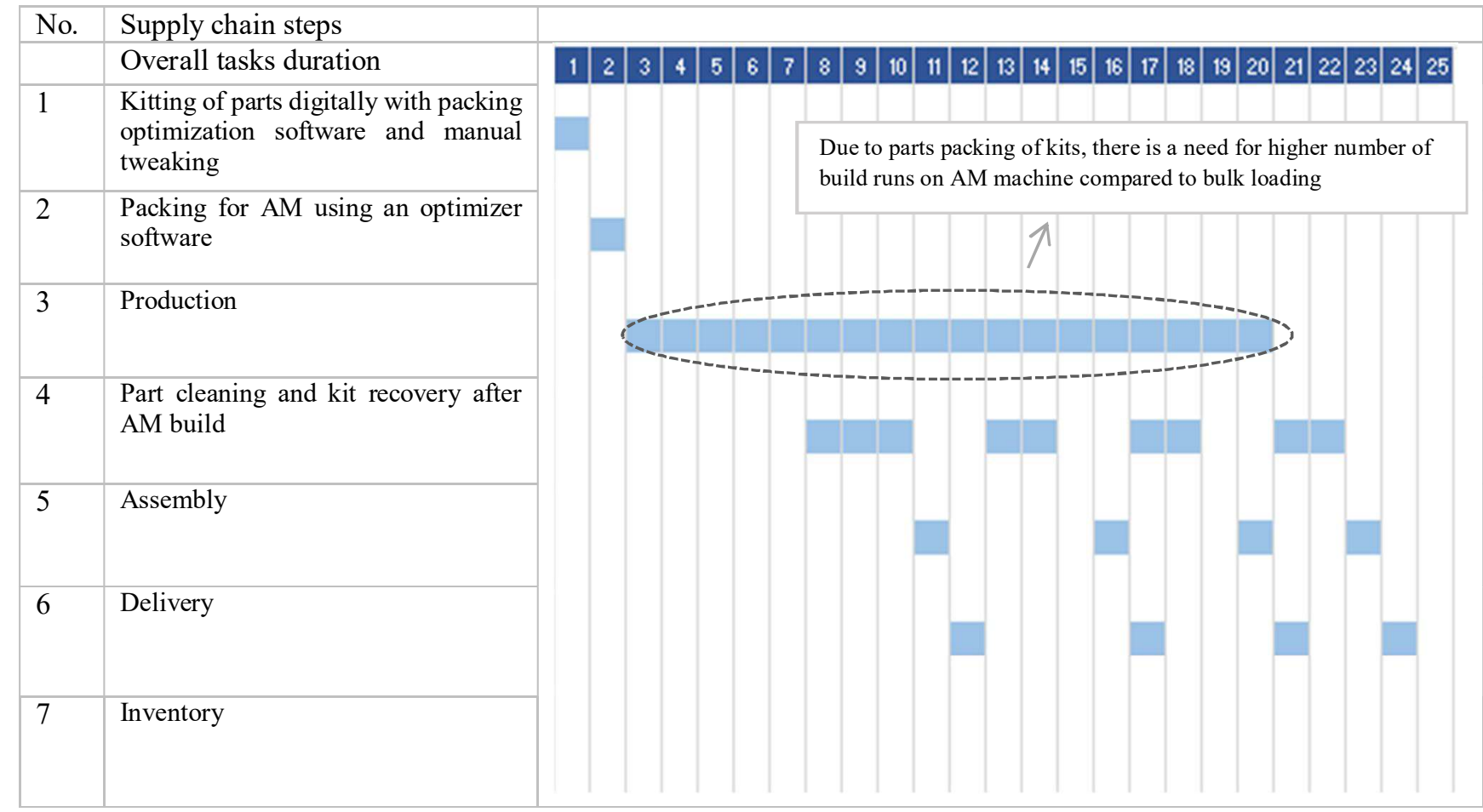

Figure 7: A schematic representation of the workflow steps for kitted LS AM products in the absence of production scheduling 


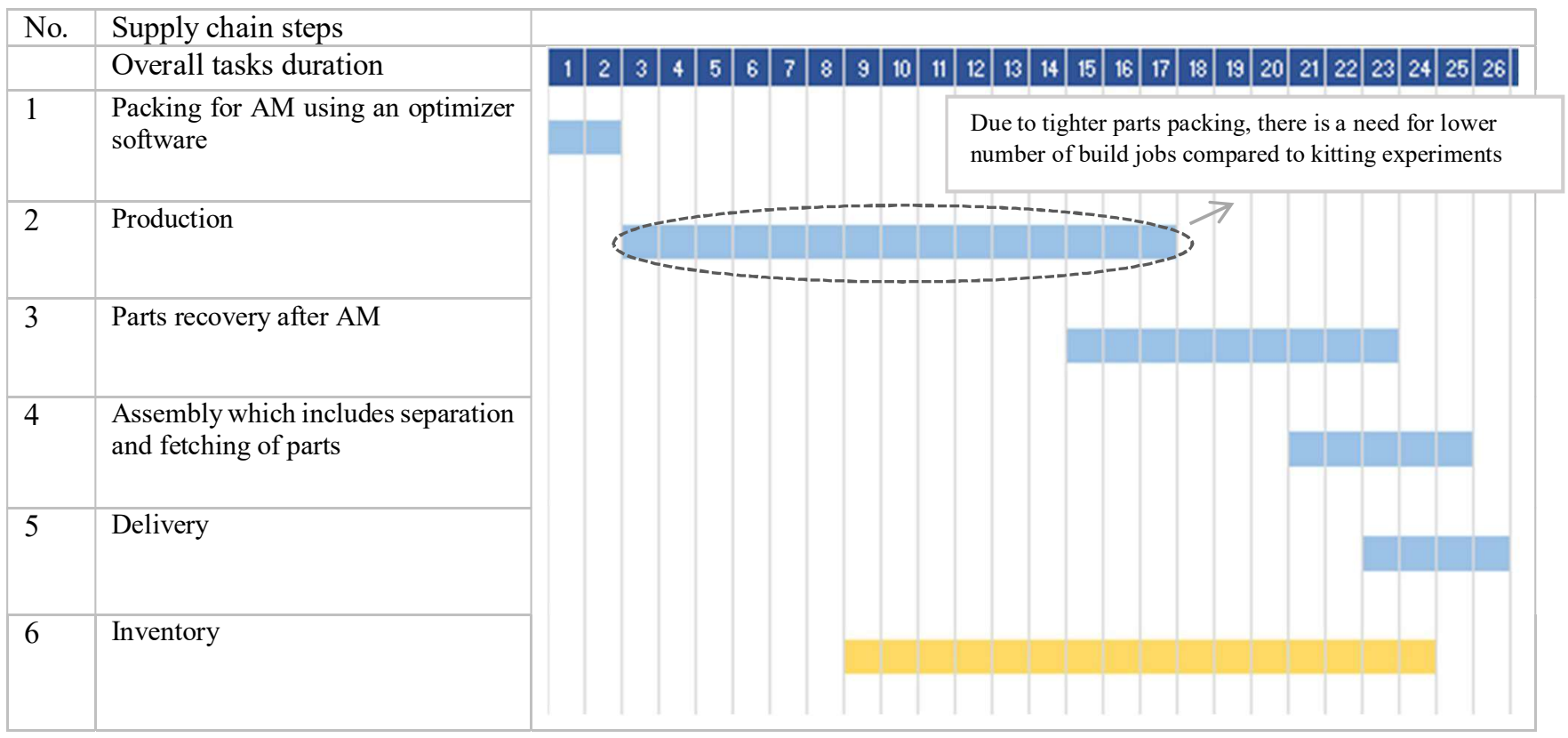

Figure 8: A schematic representation of the workflow steps for not-kitted LS AM products in the absence of production scheduling

Kitting makes the loading of the design file into the optimisation software quicker; however, it restricts the tight fitting of parts inside the LS AM machine chamber that is possible for the smaller individual parts in bulk loading. In Experiment 4, this effect is increased through the introduction of engineering requirement constraints that limit the product orientation in relation to xy-planes.

As presented in Table 5, the benefits gained from Experiment 3 are similar to benefits gained from Experiment 4 . These benefits are shorter delay for the delivery of both products and no inventory - due to the possibility of early delivery - compared to Experiments 1 and 2. In Experiments 3 and 4 kitting makes the pre-production task of loading the design files into chamber packing optimization software faster and easier. Also, the kit preparation is rapid as parts are produced together. For Experiments 1 and 2 in contrast, the collection of kits for assembly is difficult and time consuming as the parts are spread throughout different production periods.

The bottom row in Table 5 presents the potential penalties or bonuses from each Experiment's actual delivery performance. Assuming that a late delivery can impose a $\$ 2$ penalty per product per period and an early delivery provides $\$ 1$ per product per period in bonuses, then it is clear that the kitting Experiments achieved a slightly superior delivery performance among Experiments 1 to 4 (for more information, refer to Appendix E). 
Table 5: Qualitative analysis of Experiments 1, 2, 3 and 4 from a supply chain perspective

\begin{tabular}{|c|c|c|c|c|}
\hline $\begin{array}{l}\text { Supply chain } \\
\text { related aspects }\end{array}$ & Experiment 1 & Experiment 2 & Experiment 3 & Experiment 4 \\
\hline \multirow{3}{*}{$\begin{array}{l}\text { On-time delivery } \\
\text { and product } \\
\text { inventory } \\
\text { handling }\end{array}$} & \multirow{3}{*}{$\begin{array}{l}\text { Delay for the drone for one } \\
\text { period, and the inventory } \\
\text { of drones will sit until the } \\
\text { last delivery. } \\
\text { Delay for the extruder for } \\
\text { two periods, and then the } \\
\text { inventory of extruders will } \\
\text { sit until the last delivery. }\end{array}$} & \multirow{3}{*}{$\begin{array}{l}\text { Delay for the drone for one } \\
\text { period, and the inventory of } \\
\text { drones will sit until the last } \\
\text { delivery. } \\
\text { Delay for the extruder for } \\
\text { two periods, and then the } \\
\text { inventory of extruders will } \\
\text { sit until the last delivery. }\end{array}$} & No delay for the drone. & No delay for the drone. \\
\hline & & & $\begin{array}{l}\text { Extruder is delayed by } \\
\text { one period. There is one } \\
\text { back order in period } 3 \text { to } \\
\text { be delivered in } 4^{\text {th }} \\
\text { period. }\end{array}$ & $\begin{array}{l}\text { Extruder is delayed by } \\
\text { two periods. There are } \\
\text { three back orders in } \\
\text { period } 3 \text { to be delivered } \\
\text { in } 4^{\text {th }} \text { period. }\end{array}$ \\
\hline & & & $\begin{array}{l}\text { No inventory due to the } \\
\text { possibility of early } \\
\text { delivery. }\end{array}$ & $\begin{array}{l}\text { No inventory due to the } \\
\text { possibility of early } \\
\text { delivery. }\end{array}$ \\
\hline Product assembly & $\begin{array}{l}\text { The collection of kits for } \\
\text { assembly is difficult and } \\
\text { time consuming as the } \\
\text { parts are spread throughout } \\
\text { different production } \\
\text { periods. } \\
\text { There is no physical } \\
\text { guidance to assembly. }\end{array}$ & $\begin{array}{l}\text { The collection of kits for } \\
\text { assembly is difficult and } \\
\text { time consuming as the } \\
\text { parts are spread throughout } \\
\text { different production } \\
\text { periods. } \\
\text { There is no physical } \\
\text { guidance to assembly. }\end{array}$ & $\begin{array}{l}\text { The kit preparation is } \\
\text { rapid as parts are } \\
\text { produced together. } \\
\text { Assembly is not assisted } \\
\text { through physical } \\
\text { positioning of the items } \\
\text { as the secondary } \\
\text { processes dislocate the } \\
\text { parts. }\end{array}$ & $\begin{array}{l}\text { The kit preparation is } \\
\text { rapid as parts are } \\
\text { produced together. } \\
\text { Assembly is not assisted } \\
\text { through physical } \\
\text { positioning of the items } \\
\text { as the secondary } \\
\text { processes dislocate the } \\
\text { parts. }\end{array}$ \\
\hline $\begin{array}{c}\text { Secondary } \\
\text { processes }\end{array}$ & & & \multicolumn{2}{|c|}{$\begin{array}{l}\text { To preserve the kits, there is a need for slightly } \\
\text { different instructions for the manual secondary } \\
\text { steps, as well as suitable carrying containers to } \\
\text { separate the kits and avoid losing parts or mixing } \\
\text { kits. }\end{array}$} \\
\hline $\begin{array}{l}\text { Product design } \\
\text { file acquisition } \\
\text { and preparation }\end{array}$ & & & \multicolumn{2}{|c|}{$\begin{array}{l}\text { The integration of kitting into the design can be } \\
\text { achieved by software, such as 3DPackRAT, which } \\
\text { substantially streamlines the packing optimisation in } \\
\text { kit mode. }\end{array}$} \\
\hline Other aspects & & & \multicolumn{2}{|c|}{$\begin{array}{l}\text { Kitting makes the pre-production task of loading the } \\
\text { design files into chamber packing optimization } \\
\text { software faster and easier. }\end{array}$} \\
\hline $\begin{array}{l}\text { Overall delivery } \\
\text { performance } \\
\text { (penalty from } \\
\text { late delivery or } \\
\text { bonus for early } \\
\text { delivery) }\end{array}$ & Bonus of $\$ 13$ & Bonus of $\$ 13$ & Bonus of $\$ 31$ & Bonus of $\$ 16$ \\
\hline
\end{tabular}

When considering the supply chain aspects of the experiments, the total cost gap between Experiments 1 and 3 is $8.7 \%$. This gap is $16 \%$ between Experiments 2 and 4 . Therefore, the kitting scheme is not economical under all conditions, and the loss of production packing efficiency can exceed the supply chain gains in some cases. However, if we also take into account the delivery performance of experiments, where the penalty for delivery delay is $\$ 10$ per product per period and the bonus for an early delivery per product per period is $\$ 5$, then Experiment 3 becomes the most economical option. In this setting the delivery performance of Experiments 1 and 2 reduces the total cost (due to the collection of $\$ 65$ in bonuses) to $\$ 523$ and $\$ 525.9$ respectively. Meanwhile, total cost of Experiment 3 is reduced by $\$ 155$ to $\$ 484.5$ due to the possibility for early shipping while manufacturing in kits.

Experiments 1 to 4 skipped delivery planning during the build phase to achieve better chamber capacity optimization and adjust to the delivery plan in their supply chain steps right after the build. In contrast, Experiments 5, 6, 7 and 8 are designed to closely meet the delivery plan, starting from the build phase. Here, we perform an in-depth analysis of these experiments.

Experiments 5 and 7 (similar to 6 and 8) only differ with respect to bulk or kitted loading. With the introduction of the delivery time constraint to the experiments, all four experiments (Experiment 5, 6, 7 and 8) require five production runs on the LS AM machine (Appendix D). This results in even smaller build cost differences (compared to Experiments 1, 2, 3 and 4), which is only a 4.3\% cost advantage for Experiment 5 compared to Experiment 7 and a 10.1\% build cost advantage for Experiment 6 compared 
to Experiment 8. This slight advantage is exceeded by the supply chain expenses for Experiments 5 and 7 , where the total cost of operation is approximately the same.

Similar to Experiments 1 and 2, in Experiments 5 and 6 the producer should address parts sorting and subsequent part fetching for assembly feed in addition to work-in-progress inventory (Table 6). These two disadvantages are the consequence of tighter parts packing enabled by bulk loading, which lowers the production cost while complicating the forthcoming supply chain tasks. According to Table 6, this does not occur in Experiments 7 and 8 because they produce all of the required product assembly components, which enables early delivery (no work-in-progress inventory) and less time-consuming assembly (lack of part sorting and fetching). However, early delivery can lead to additional transportation (or inventory) costs. For instance, while Experiments 5 and 6 meet the customers demand with only 8 deliveries, Experiments 7 and 8 both require 9 deliveries.

According to Table 6, all four experiments $(5,6,7$ and 8$)$ meet the delivery schedule. There are two downsides for pre-set kitting from an overall supply chain perspective, in addition to the higher build cost. Kitting requires an additional step after the completion of the products' CAD design: the one-time digital creation of the kit. Moreover, kits require slightly different post-production handling, which requires the technician to understand the concept of kitting and the approximate shape of the produced kits (Table 6). Regarding order delivery performance, Experiments 7 and 8 are marginally better due to the possibility for early delivery of products.

Table 6: Qualitative analysis of Experiments 5, 6, 7 and 8 from a supply chain perspective

\begin{tabular}{|c|c|c|c|c|}
\hline $\begin{array}{l}\text { Supply chain } \\
\text { related aspects }\end{array}$ & Experiment 5 & Experiment 6 & Experiment 7 & Experiment 8 \\
\hline $\begin{array}{l}\text { On-time delivery } \\
\text { and product } \\
\text { inventory handling }\end{array}$ & $\begin{array}{l}\text { No delay. } \\
\text { Inventory of parts exists } \\
\text { between the periods until } \\
\text { the last delivery. }\end{array}$ & $\begin{array}{l}\text { No delay. } \\
\text { Inventory of parts exists } \\
\text { between the periods until } \\
\text { the last delivery. }\end{array}$ & $\begin{array}{l}\text { No delay and no } \\
\text { inventory. }\end{array}$ & $\begin{array}{l}\text { No delay and no } \\
\text { inventory. }\end{array}$ \\
\hline Product assembly & $\begin{array}{l}\text { The collection of kits for } \\
\text { assembly is difficult and } \\
\text { time consuming as some } \\
\text { of the parts are spread } \\
\text { throughout different } \\
\text { production periods. } \\
\text { There is no physical } \\
\text { guidance to assembly. }\end{array}$ & $\begin{array}{l}\text { The collection of kits for } \\
\text { assembly is difficult and } \\
\text { time consuming as the } \\
\text { parts are spread } \\
\text { throughout different } \\
\text { production periods. } \\
\text { There is no physical } \\
\text { guidance to assembly }\end{array}$ & $\begin{array}{l}\text { The kit making is rapid } \\
\text { as parts are produced } \\
\text { together. } \\
\text { Assembly is not assisted } \\
\text { through physical } \\
\text { positioning of the items } \\
\text { as the secondary } \\
\text { processes dislocate the } \\
\text { parts. }\end{array}$ & $\begin{array}{l}\text { The kit making is rapid } \\
\text { as parts are produced } \\
\text { together. } \\
\text { Assembly is not assisted } \\
\text { through physical } \\
\text { positioning of the items } \\
\text { as the secondary } \\
\text { processes dislocate the } \\
\text { parts. }\end{array}$ \\
\hline $\begin{array}{l}\text { Secondary } \\
\text { processes }\end{array}$ & & & \multicolumn{2}{|c|}{$\begin{array}{l}\text { To preserve the kits there is a need for slightly } \\
\text { different instruction for manual secondary steps as } \\
\text { well as suitable carrying containers to separate the } \\
\text { kits and avoid losing parts or mixing kits. }\end{array}$} \\
\hline $\begin{array}{l}\text { Product design file } \\
\text { acquisition and } \\
\text { preparation }\end{array}$ & & & \multicolumn{2}{|c|}{$\begin{array}{l}\text { The kitting integration into the design can be done } \\
\text { by a software like 3DPackRAT which significantly } \\
\text { streamlines the packing optimisation in kit mode. }\end{array}$} \\
\hline Other aspects & & & \multicolumn{2}{|c|}{$\begin{array}{l}\text { Kitting makes the pre-production task of loading the } \\
\text { design files into chamber packing optimization } \\
\text { software faster and easier. }\end{array}$} \\
\hline $\begin{array}{c}\text { Overall delivery } \\
\text { performance } \\
\text { (penalty from late } \\
\text { delivery or bonus } \\
\text { for early delivery) }\end{array}$ & None & None & Bonus of $\$ 1$ & Bonus of $\$ 3$ \\
\hline
\end{tabular}

The reason behind the cost competitiveness of Experiment 7 is that, in contrast to Experiment 3, which required one more production run than Experiment 1, the introduction of the production schedule increases the number of production runs in Experiment 5 to five, which is equal to that of Experiment 7. Moreover, Experiment 7 does not suffer from the packing disadvantage of Experiment 8 which has engineering constraints that limit the kits orientation. These two factors, coupled with the existence of the supply chain costs (e.g., cost of inventory carrying, production planning and control, and part sorting 
and fetching) in Experiment 5, increase the cost competitiveness of the kitting experiment by about $4.5 \%$ (over the build cost comparison of Experiments 5 and 7).

With regard to the workflow representation, all four experiments $(5,6,7$ and 8$)$ are similar to the workflow chart presented in Figure 7, except that the production run is longer and there are five production runs in each experiment. Moreover, Experiments 5 and 6 need to carry inventory from the end of the first production run until the beginning of the last assembly session. The implementation of the delivery schedule for AM brings the benefits of parallel operations to bulk production, reducing the overall time advantage of kitting. However, it does not reduce the labour intensiveness of bulk loading compared to kitting (e.g., the need for a production planning and control function, less efficient assembly feed, time-consuming $\mathrm{CAD}$ design preparation and the need for work-in-progress parts inventory). In other words, as expected, kitting increases the time spent on the machine while reducing the overall labour intensiveness of production.

\section{Discussion}

Pre-set kitting parts handling for LS additive manufacturing is most suitable for the production of an array of products that possess the following metrics:

- Products are assembled in parallel work stations rather than on production lines

- High product variety and customization (traceability requirements)

- Large number of assembly parts

- The delivery performance is important, due to high penalties or bonuses

- Inventory carrying cost is high or there is a risk of obsolescence

In such cases, pre-set kitting for AM through the digitalization of the kit preparation step (integration into the design model) simplifies assembly operations while avoiding significant additional costs due to the preparation steps. Moreover, it streamlines production planning and control - as well as the preproduction steps related to products loading into the LS AM machine software - and enables early delivery and zero inventory (i.e., work-in-progress parts and final products). Although the supply chain related aspects of kitting (simplified assembly process, no WIP inventory management and transportation) improve the overall cost competitiveness, they might not be sufficient to offset the production cost disadvantages of utilising kits for AM.

To reduce the cost of kitting in AM, we propose printing a combination of kits and bulk parts. In this way, individual parts from a bulk pool can be inserted to fill the gaps created by the kit arrangement. This can improve the chamber utilisation and reduce the overall cost. In such a setting, the suitable bulk part candidates are those that have more flexible delivery schedules and those that are independent items (not part of an assembly). A hybrid bulk-kit parts loading for LS AM benefits from the efficiency of production (through tighter packing) while reducing the labour intensiveness of supply chain tasks (streamlined assembly). A potential drawback of the hybrid loading method is the introduction of WIP inventory that results from utilising the sub-sections of other assemblies to fill the production volume.

In another scheme to improve the kitting economics, we suggest separating parts with engineering constraints from the other parts of a kit to reduce the negative impact of the fixed orientation. For instance, parts with constraints can be loaded into the optimisation software individually or as a separate kit containing other constrained parts.

Moreover, as the results of our analysis suggest, optimised packing of each individual kit plays an essential role in the overall cost performance of the kitting scheme; we propose flexible kitting. In such a setting, the components of a kit can be treated by the optimisation software as a flexible group of parts 
that can be rearranged according to the packing conditions to achieve the highest build efficiency while keeping all the components of individual kits in close proximity. Under these conditions, kit loading benefits from packing efficiencies close to those of bulk loading, with one limitation that prevents parts that belong to a single kit from being spread across multiple build chambers. This implies, as seen before, the underpinning requirement of integrated optimisation approaches spanning multiple steps in digital supply chains.

\section{Conclusions}

Additive manufacturing (and especially polymer-based laser sintering) is increasingly used for final production of parts and assemblies in low to medium volumes (e.g., aircraft cooling ducts), and increasingly affordable AM machines are emerging (e.g., Sinterit and Sintratec LS machines). Therefore, it is important to study plausible manufacturing practices to improve manufacturing supply chain reliability and reduce costs. In this research, we investigated the benefits and shortcomings of a parts-handling strategy for AM called pre-set kitting. The concept of kitting, which is well known in the electronics and auto industries, has not received enough attention in the field of AM. This paper is a direct answer to the call for exploratory research in this field by Lyly-Yrjänäinen et al. [28] who studied the benefits of kitting in a non-AM production system. Since the main drawback of kitting in traditional manufacturing is due to the labour-intensive preparation of kits, the use of kitting for AM makes sense as this step no longer exists. Parts can be packed into kits after the initial creation of design files, which can be used an unlimited number of times for loading into the additive manufacturing machines.

Eight experiments were designed to conduct an impact analysis of parts kitting in AM with respect to production and a more holistic supply chain. The experiments were conducted on a polymer-based LS AM machine and home-grown chamber packing optimization software. The results clearly showed a build cost disadvantage (of up to approximately $31 \%$ ) for pre-set parts kitting due to the less efficient production chamber volume utilisation. However, the introduction of additional constraints, such as engineering requirements (and delivery schedule), negatively impacted the production costs of bulkloaded experiments compared to kitted experiments.

From a broader supply chain perspective, since the kit preparation step is digitalized and is no longer labour intensive, physical kitting benefits can be achieved. These benefits, are as follows: higher assembly feed efficiency and lower space requirements due to the absence of WIP inventory [8], less need for production planning, possibility for parallel performance of supply chain tasks, early delivery and increased time efficiency of the build volume optimisation step (due to the simultaneous loading of parts in pre-set kits). These benefits can potentially offset the kitting production cost disadvantage when the variety of products is high, labour and/or inventory space shortages exist, and/or the supply chain product delivery performance is important, however more research is required in this area. Experiment 7 in our research was the only kitting example with lower total cost than its bulk counterpart in the normal conditions. This is significant as it proves the point with regard to the cost benefits gained throughout the supply chain from the implementation of kitting in AM. Additionally, when a penalty and bonus regime was set for order delivery performance, Experiment 3 became the most economical one due to making early deliveries and having fewer delays.

On the other hand, implementation of kitting for LS AM parts loading has a few drawbacks. Kitting requires a one-time digital kit-making task after the object design is complete. Although this process can be automated with human supervision, because this step does not exist in bulk loading, we mention it as a shortcoming. Moreover, a slightly different parts recovery process will need to be performed after the print job is complete. This includes the technician's overall and specific knowledge of the kits used in each production job. 
A hybrid loading method is also discussed in this paper which combines kit loading with bulk loading to boost the efficiency of part loading in kit mode for LS AM. Hybrid parts packing may result in lower overall cost through better production volume capacity utilisation and supply chain related benefits, such as improved parts loading and assembly time efficiency, however more research is required.

In contrast to traditional kitting, the only significant obstacle limiting kitting implementation for all multi-parts additively manufactured products is the high initial investment cost of the LS AM machine, which makes chamber under-utilisation expensive. Therefore, the inherent issue of kitting (i.e., the preparation step) is no longer a significant obstacle to wider utilisation.

One of the disadvantages for the kitting build cost estimation was related to the limitations of the packing optimisation software. After each kit is digitally prepared and the .stl file is created, the packing optimisation software treats the multi-part kit as a single object, which can result in serious utilisation disadvantages. In other words, components included in a kit remain as they were packed by the kit maker regardless of the arrangement of the production chamber. Therefore, there is high potential for kitting build cost reduction if the software provides a feature to rearrange and optimise the parts inside each kit according to each build job (the whole production chamber). Future research may evaluate the potential benefits of such capability with respect to kitting economics and competitiveness.

As the volume of production and variety of parts increases, it is likely that the complexity of the production planning and control functions will become a problem in AM bulk loading. Therefore, an important topic for further research is how to introduce a cyber-physical link between the part and its virtual counterpart. We propose that such a link would enable product-centric planning and handling, presenting many opportunities to reduce the planning and control costs for both AM bulk loading and pre-set kitting, as well as reducing the supply chain and product life-cycle management costs $[12,13]$.

This article studied polymer 3D printing by LS process; however, other technologies and raw materials (e.g., metals) that have different workflows and requirements (e.g., necessity to produce supports underneath the overhangs) that influence the cost modelling and calculations, should also be investigated. Moreover, we proposed a hybrid loading procedure where a combination of kits and bulk parts can be loaded in a single chamber to reduce the build cost while maintaining the supply chain efficiencies of kitting. A quantitative analysis of hybrid loading can provide the managerial implications for its use in AM production planning and scheduling.

\section{References}

1. Araújo, L.J.P., Özcan, E., Atkin, J., Baumers, M., Tuck, C. and Hague, R., 2015. Toward better build volume packing in additive manufacturing: classification of existing problems and benchmarks.

2. Baumers M., Özcan E. and Atkin J., (2016). Executive summary. 3D Printing Production Planning: Reactive manufacturing execution driving redistributed manufacturing - Project Report. Available at: http://www.3dpackrat.com/

3. Baumers, M., Tuck, C., Wildman, R., Ashcroft, I., \& Hague, R. (2011). Energy inputs to additive manufacturing: does capacity utilization matter?. EOS, 1000(270), 30-40.

4. Baumers, M., Tuck, C., Wildman, R., Ashcroft, I., Rosamond, E., \& Hague, R. (2013). Transparency Built-in. Journal of Industrial Ecology, 17(3), 418-431.

5. Bozer, Y. A., \& McGinnis, L. F. (1984). Kitting: a generic descriptive model. Material Handling Research Center, Georgia Institute of Technology.

6. Bozer, Y. A., \& McGinnis, L. F. (1992). Kitting versus line stocking: a conceptual framework and a descriptive model. International Journal of Production Economics, 28(1), 1-19.

7. Brennan, R. W. (2000). Performance comparison and analysis of reactive and planning-based control architectures for manufacturing. Robotics and Computer-Integrated Manufacturing, 16(2), 191-200. 
8. Caputo, A. C., and P. M. Pelagagge. (2011). "A Methodology for Selecting Assembly Systems Feeding Policy.” Industrial Management \& Data Systems 1 (111): 84-112.

9. Engström, T., Johansson, J. Å., Jonsson, D., \& Medbo, L. (1995). Empirical evaluation of the reformed assembly work at the Volvo Uddevalla plant: Psychosocial effects and performance aspects. International Journal of Industrial Ergonomics, 16(4-6), 293-308.

10. Engström, T., Jonsson, D., \& Johansson, B. (1996). Alternatives to line assembly: some Swedish examples. International Journal of Industrial Ergonomics, 17(3), 235-245.

11. Engström, T., Jonsson, D., \& Medbo, L. (1998). The Volvo Uddevalla plant and interpretations of industrial design processes. Integrated Manufacturing Systems, 9(5), 279-295.

12. Främling, K., Ala-Risku, T., Kärkkäinen, M., \& Holmström, J. (2007). Design patterns for managing product life cycle information. Communications of the ACM, 50(6), 75-79.

13. Främling, K., Ala-Risku, T., Kärkkäinen, M., \& Holmström, J. (2006). Agent-based model for managing composite product information. Computers in Industry, 57(1), 72-81.

14. Frazier, W. E. (2014). Metal additive manufacturing: a review. Journal of Materials Engineering and Performance, 23(6), 1917-1928.

15. Freedman, D. H. (2011). Layer by Layer: with 3-D printing, manufacturers can make existing products more efficiently — and create ones that weren't possible before. MIT Technology Review. Available at: https://www.technologyreview.com/s/426391/layer-by-layer/ (Accessed on June 1st 2017)

16. Freyssenet, M. (1998). 'Reflective Production': An Alternative to Mass Production and Lean Production?. Economic and industrial democracy, 19(1), 91-117.

17. Gibson, I., Rosen, D. W., \& Stucker, B. (2010). Additive manufacturing technologies (Vol. 238). New York: Springer.

18. Hanson, R., \& Medbo, L. (2012). Kitting and time efficiency in manual assembly. International Journal of Production Research, 50(4), 1115-1125.

19. Hanson, R., Medbo, L., \& Medbo, P. (2012). Assembly station design: a quantitative comparison of the effects of kitting and continuous supply. Journal of Manufacturing Technology

Management, 23(3), 315-327.

20. Hanson, R., and A. Brolin. (2013). “A Comparison of Kitting and Continuous Supply in in-plant Materials Supply.” International Journal of Production Research 51 (4).

21. Holmström, J., Holweg, M., Khajavi, S. H., \& Partanen, J. (2016). The direct digital manufacturing (r) evolution: definition of a research agenda. Operations Management Research, 9(1-2), 1-10.

22. Holmström, J., Partanen, J., Tuomi, J., \& Walter, M. (2010). Rapid manufacturing in the spare parts supply chain: alternative approaches to capacity deployment. Journal of Manufacturing Technology Management, 21(6), 687-697.

23. Hopkinson, N., Hague, R., \& Dickens, P. (Eds.). (2006). Rapid manufacturing: an industrial revolution for the digital age. John Wiley \& Sons.

24. Hua, S. Y., and D. J. Johnson. (2010). "Research Issues on Factors Influencing the Choice of Kitting versus Line Stocking." International Journal of Production Research 48 (3)

25. Johansson, M. I. (1991). Kitting systems for small size parts in manual assembly systems.

26. Khajavi, S. H., Partanen, J., \& Holmström, J. (2014). Additive manufacturing in the spare parts supply chain. Computers in industry, 65(1), 50-63.

27. Kruth, J. P., Leu, M. C., \& Nakagawa, T. (1998). Progress in additive manufacturing and rapid prototyping. CIRP Annals-Manufacturing Technology, 47(2), 525-540.

28. Lyly-Yrjänäinen, J., Holmström, J., Johansson, M. I., \& Suomala, P. (2016). Effects of combining product-centric control and direct digital manufacturing: The case of preparing customized hose assembly kits. Computers in Industry, 82, 82-94.

29. Microsoft, 2017. Generate a 3MF package. Windows Dev Center. Available at $\mathrm{https://msdn.microsoft.com/windows/uwp/devices-sensors/generate-3mf} \mathrm{(Accessed} \mathrm{on} \mathrm{March} \mathrm{3rd}$ 2017)

30. Muffatto, M. (1999). Evolution of production paradigms: the Toyota and Volvo cases. Integrated Manufacturing Systems, 10(1), 15-25. 
31. Pil, F. K., \& Fujimoto, T. (2007). Lean and reflective production: the dynamic nature of production models. International journal of production research, 45(16), 3741-3761.

32. Ruffo, M., \& Hague, R. (2007). Cost estimation for rapid manufacturing'simultaneous production of mixed components using laser sintering. Proceedings of the Institution of Mechanical Engineers, Part B: Journal of Engineering Manufacture, 221(11), 1585-1591.

33. Ruffo, M., Tuck, C., \& Hague, R. (2006). Cost estimation for rapid manufacturing-laser sintering production for low to medium volumes. Proceedings of the Institution of Mechanical Engineers, Part B: Journal of Engineering Manufacture, 220(9), 1417-1427.

34. Sali, M., Sahin, E., \& Patchong, A. (2015). An empirical assessment of the performances of three line feeding modes used in the automotive sector: line stocking vs. kitting vs. sequencing. International Journal of Production Research, 53(5), 1439-1459.

35. Tuck, C. J., Hague, R. J., Ruffo, M., Ransley, M., \& Adams, P. (2008). Rapid manufacturing facilitated customization. International Journal of Computer Integrated Manufacturing, 21(3), 245258.

36. Pannequin, R., Morel, G., \& Thomas, A. (2009). The performance of product-driven manufacturing control: An emulation-based benchmarking study. Computers in Industry, 60(3), 195-203.

37. Boysen, N., \& Bock, S. (2011). Scheduling just-in-time part supply for mixed-model assembly lines. European Journal of Operational Research, 211(1), 15-25.

38. Medbo, L. (2003). Assembly work execution and materials kit functionality in parallel flow assembly systems. International Journal of Industrial Ergonomics, 31(4), 263-281.

\section{Acknowledgements}

We would like to express our sincere thanks to the European Institute of Technology for providing funding for this research visit and to Mr. Mark East of the University of Nottingham for providing significant assistance in conducting the additive manufacturing production experiment. 


\section{Appendices}

\section{Appendix A: Explanation of the experiments}

Products $\mathrm{A}$ and $\mathrm{B}$ are assumed to have the delivery order shown in Table 7, which requires a total of 21 drones and 8 extruder assemblies to be delivered by the end of the period (working week).

Table 7: Random production delivery plan for Products A and B

\begin{tabular}{r|c|c} 
& \multicolumn{2}{|c}{ Delivery schedule } \\
\hline Period (day) & Product A (drone) & $\begin{array}{l}\text { Product B (3D printer } \\
\text { extruder component) }\end{array}$ \\
\hline 1 & 1 & 2 \\
\hline 2 & 10 & 1 \\
\hline 3 & 0 & 4 \\
\hline 4 & 7 & 0 \\
\hline 5 & 3 & 1 \\
\hline Total & $\mathbf{2 1}$ & $\mathbf{8}$
\end{tabular}

The production delivery plan is randomized by Excel software using the RANDBETWEEN function and boundaries of 0 to 16 for Product A (because 16 kits of this product, packed by 3DPackRAT, fill the production chamber of our test machine) and 0 to 4 for Product B (because 4 kits of this product, packed by 3DPackRAT, fill the production chamber of our test machine).

To compare the build costs of the experiments where kitting is used to cost when bulk loading of the parts is used, a pre-set kit was produced by loading all the components of the assembly into our packing optimiser and manually adjusting the kit for slight improvements with regard to the z-axis. Figures 10 illustrate the products kits while, Figure 11 illustrates the production chamber loading in bulk versus production chamber loading via kits.

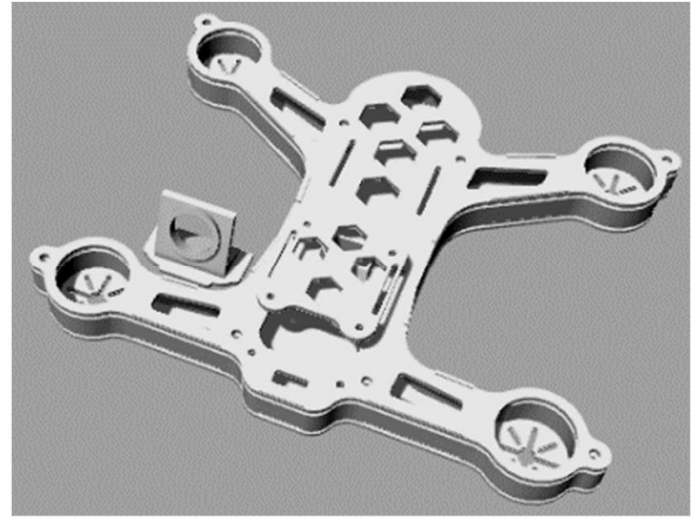

Product A in kit mode

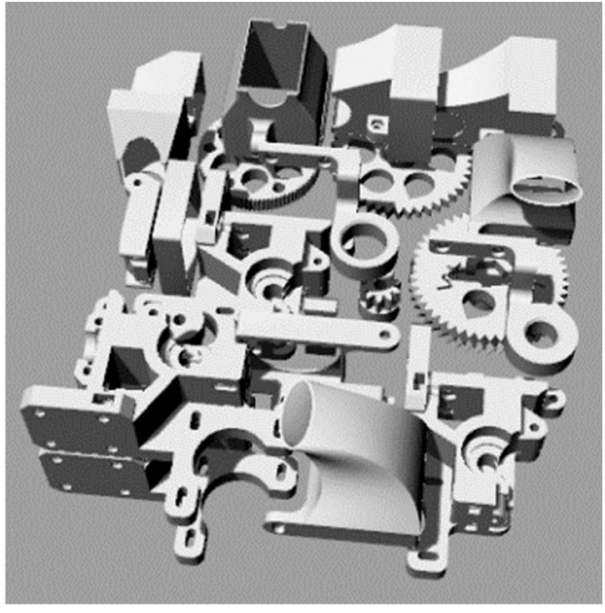

Product B in kit mode

Figure 10: Product kits used in this research 


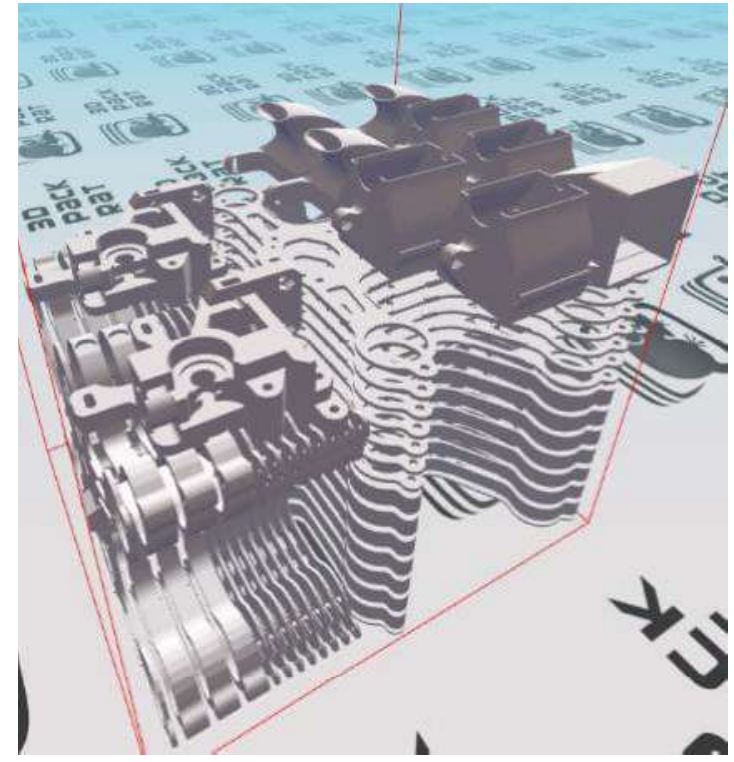

Loading in bulk mode, where parts are mixed together and tightly packed but some components of each assembly are not necessarily included in every production run

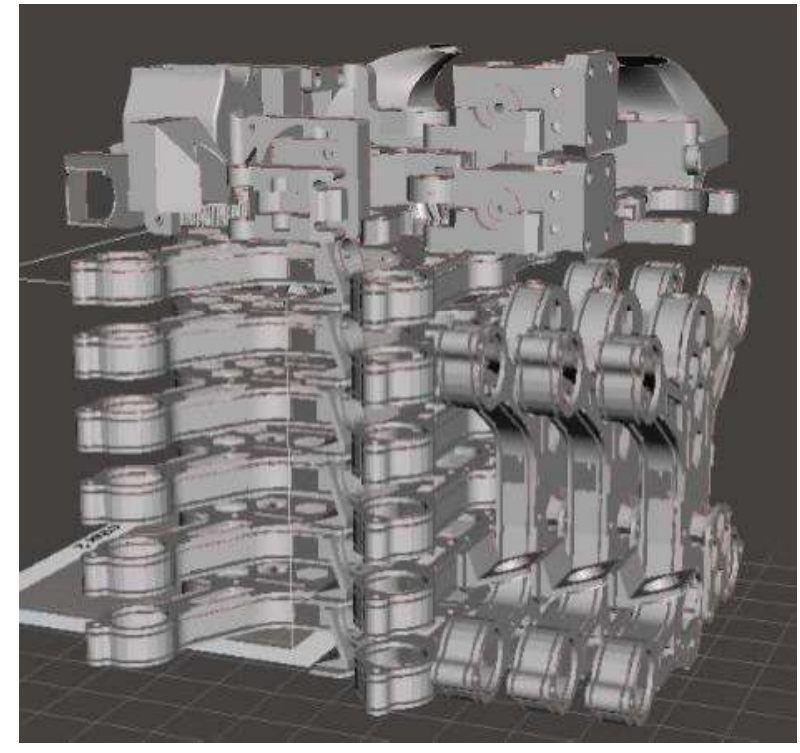

Loading in kits mode, where assignment of space is not as efficient as that in bulk loading; however, all the parts of each assembly are present in the build chamber

Figure 11: Production chamber loading difference

To explain the method of loading the parts into the software for each experiment, we use Experiment 1 as an example. For the Experiment 1, the total number of orders for each product $(21 \& 8)$ is loaded into the machine (software), part by part, each time, along with the required quantity. For instance, orders for part 1 of the drone are placed 21 times before orders for part 2 are placed, and so on. Orders for parts of product two are not placed until all parts of product one have been completed. Capacity optimisation without consideration of the schedule or any other constraints is the aim in this experiment. Moreover, since there are no constraints on the product engineering requirements, parts can rotate for the optimal packing of the production chamber. The optimised output from the software for the second day is illustrated in Figure 12.

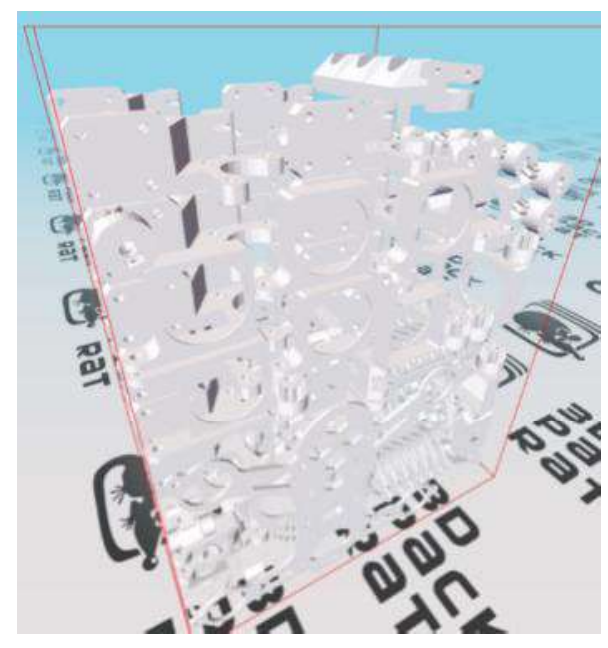

Figure 12: A mix of 144 parts are being packed for the second production run on LS AM machine in Experiment 1 
In the kit mode, 16 assembly kits of Product A or 4 assembly kits of Product B packed in optimise manner by 3DPackRAT software (without parts orientation constraints) fill the EOSINT P100 chamber.

\section{Appendix B: General production cost modelling data and assumptions}

The data in Table 8 are utilised in our production cost calculations.

Table 8: The data for laser sintering with EOSINT P100

\begin{tabular}{lcc} 
Machine initial investment (\$) & 215,000 & $75 \%$ \\
\hline Annual availability of machine (hrs/yr) & 6570 & $7 \%$ \\
\hline Life span of machine (years) & 10 & \\
\hline Annual maintenance (\$) & 15,050 & 0.1 \\
\hline Layer thickness (mm) & $19.7^{*}$ & $121.5^{*}$ \\
\hline Average recoating time (seconds) & Time for the laser to scan the whole surface \\
(seconds) & *These values are calculated meticulously for this job and EOSINT P100 after the experimental production run and in-depth \\
analysis of the AM machine production log. &
\end{tabular}




\section{Appendix C: 3DPackRAT optimisation software output for the eight experiments}

Table 9 presents the LS build flow and its details regarding the number of production runs in each experiment and the number of produced parts per run.

Table 9: The build flow details in each experiment

\begin{tabular}{|c|c|c|c|c|c|c|c|c|c|}
\hline & & Experiment 1 & $\begin{array}{l}\text { Experiment } \\
2\end{array}$ & $\begin{array}{l}\text { Experiment } \\
3\end{array}$ & $\begin{array}{l}\text { Experiment } \\
4\end{array}$ & $\begin{array}{l}\text { Experiment } \\
5\end{array}$ & $\begin{array}{l}\text { Experiment } \\
6\end{array}$ & $\begin{array}{l}\text { Experiment } \\
7\end{array}$ & $\begin{array}{l}\text { Experiment } \\
8\end{array}$ \\
\hline & - & $\begin{array}{l}\text { Build ID } \\
\text { M-0000-0 } \\
\text { Utilisation } \\
15,5 \% \\
\text { Total Parts } \\
106 \\
\text { Parts on Tim } \\
106\end{array}$ & $\begin{array}{l}\text { Build ID } \\
\text { M-0000- } 0 \\
\text { Utilisation } \\
15,1 \% \\
\text { Total Parts } \\
182 \\
\text { Parts on Tin- } \\
182\end{array}$ & $\begin{array}{l}\text { Build ID } \\
\text { M-0000-0 } \\
\text { Utilisation } \\
6.43 \% \\
\text { Total Parts } \\
16 \\
\text { Parts on Tim } \\
16\end{array}$ & $\begin{array}{l}\text { Build ID } \\
\text { M-0000-0 } \\
\text { Utilisation } \\
4.02 \% \\
\text { Total Parts } \\
10 \\
\text { Parts on Tin } \\
10\end{array}$ & $\begin{array}{l}\text { Build ID } \\
\text { M-0000-0 } \\
\text { Utilisation } \\
7.06 \% \\
\text { Total Parts } \\
101 \\
\text { Parts on Tim } \\
101\end{array}$ & $\begin{array}{l}\text { Build ID } \\
\text { M-0000-0 } \\
\text { Utilisation } \\
6,99 \% \\
\text { Total Parts } \\
77 \\
\text { Parts on Tinn } \\
77\end{array}$ & $\begin{array}{l}\text { Build ID } \\
\text { M-0000-0 } \\
\text { Utilisation } \\
5.01 \% \\
\text { Total Parts } \\
4 \\
\text { Parts on Tin } \\
4\end{array}$ & $\begin{array}{l}\text { Build ID } \\
\text { M-0000- } 0 \\
\text { Utilisation } \\
7.51 \% \\
\text { Total Parts } \\
6 \\
\text { Parts on Tin } \\
6\end{array}$ \\
\hline & $N$ & $\begin{array}{l}\text { Build ID } \\
\text { M-0001-0 } \\
\text { Utilisation } \\
12.1 \% \\
\text { Total Parts } \\
144 \\
\text { Parts on Tim } \\
0\end{array}$ & $\begin{array}{l}\text { Build ID } \\
\text { M-0001- } \\
\text { Utilisation } \\
8,91 \% \\
\text { Total Parts } \\
99 \\
\text { Parts on Tin- } \\
0\end{array}$ & $\begin{array}{l}\text { Build ID } \\
\text { M-0001 }-0 \\
\text { Utilisation } \\
6.21 \% \\
\text { Total Parts } \\
7 \\
\text { Parts on Tim } \\
0\end{array}$ & $\begin{array}{l}\text { Build ID } \\
\text { M-0.001-0 } \\
\text { Utilisation } \\
4.02 \% \\
\text { Total Parts } \\
10 \\
\text { Parts on Tin } \\
0\end{array}$ & $\begin{array}{l}\text { Build ID } \\
\text { M-0001-0 } \\
\text { Utilisation } \\
8,43 \% \\
\text { Total Parts } \\
44 \\
\text { Parts on Tim } \\
44\end{array}$ & $\begin{array}{l}\text { Build ID } \\
\text { M-0001-0 } \\
\text { Utilisation } \\
9.80 \% \\
\text { Total Parts } \\
76 \\
\text { Parts on Tin } \\
76\end{array}$ & $\begin{array}{l}\text { Build ID } \\
\text { M-0001-0 } \\
\text { Utilisation } \\
5,7296 \\
\text { Total Parts } \\
10 \\
\text { Parts on Tin } \\
10\end{array}$ & $\begin{array}{l}\text { Build ID } \\
\text { M-0001-0 } \\
\text { Utilisation } \\
3.22 \% \\
\text { Total Parts } \\
8 \\
\text { Parts on Tin } \\
8\end{array}$ \\
\hline $\begin{array}{l}\infty \\
0 \\
0 \\
0 \\
0 \\
0\end{array}$ & $m$ & $\begin{array}{l}\text { Build ID } \\
\text { M-0002-0 } \\
\text { Utilisation } \\
5,61 \% \\
\text { Total Parts } \\
63 \\
\text { Parts on Tim } \\
0 .\end{array}$ & $\begin{array}{l}\text { Build ID } \\
\text { M-0002-0 } \\
\text { Utilisation } \\
9.19 \% \\
\text { Total Parts } \\
32 \\
\text { Parts on Tin- } \\
0\end{array}$ & $\begin{array}{l}\text { Build ID } \\
\text { M-0002-0 } \\
\text { Utilisation } \\
8,41 \% \\
\text { Total Parts } \\
4 \\
\text { Parts on Tim } \\
0\end{array}$ & $\begin{array}{l}\text { Build ID } \\
\text { M- } 0002-0 \\
\text { Utilisation } \\
8,81 \% \\
\text { Total Parts } \\
5 \\
\text { Parts on Tin- } \\
0\end{array}$ & $\begin{array}{l}\text { Build ID } \\
\text { M-0002-0 } \\
\text { Utilisation } \\
7.89 \% \\
\text { Total Parts } \\
99 \\
\text { Parts on Tim } \\
99\end{array}$ & $\begin{array}{l}\text { Build ID } \\
\text { M-0002-0 } \\
\text { Utilisation } \\
6.51 \% \\
\text { Total Parts } \\
84 \\
\text { Parts on Tin } \\
84\end{array}$ & $\begin{array}{l}\text { Build ID } \\
\text { M=0002-0 } \\
\text { Utilisation } \\
8.41 \% \\
\text { Total Parts } \\
4 \\
\text { Parts on Tin } \\
4\end{array}$ & $\begin{array}{l}\text { Build ID } \\
\text { M-0002-0 } \\
\text { Utilisation } \\
8.41 \% \\
\text { Total Parts } \\
4 \\
\text { Parts on Tin } \\
4\end{array}$ \\
\hline & $\nabla$ & & & $\begin{array}{l}\text { Build ID } \\
\text { M-0003-0 } \\
\text { Utilisation } \\
4.20 \% \\
\text { Total Parts } \\
2 \\
\text { Parts on Tim } \\
0\end{array}$ & $\begin{array}{l}\text { Build ID } \\
\text { M-0003-0 } \\
\text { Utilisation } \\
8.41 \% \\
\text { Total Parts } \\
4 \\
\text { Parts on Tin } \\
0\end{array}$ & $\begin{array}{l}\text { Build ID } \\
\text { M-0003-0 } \\
\text { Utilisation } \\
5,39 \% \\
\text { Total Parts } \\
29 \\
\text { Parts on Tim } \\
29\end{array}$ & $\begin{array}{l}\text { Build ID } \\
\text { M-0003-0 } \\
\text { Utilisation } \\
6.35 \% \\
\text { Total Parts } \\
42 \\
\text { Parts on Tin } \\
42\end{array}$ & $\begin{array}{l}\text { Build ID } \\
\text { M-0003-0 } \\
\text { Utilisation } \\
2.81 \% \\
\text { Total Parts } \\
7 \\
\text { Parts on Tin } \\
7\end{array}$ & $\begin{array}{l}\text { Build ID } \\
\text { M-0003-0 } \\
\text { Utilisation } \\
2.81 \% \\
\text { Total Parts } \\
7 \\
\text { Parts on Tin } \\
7\end{array}$ \\
\hline & $n$ & & & & & $\begin{array}{l}\text { Build ID } \\
\text { M-0004-0 } \\
\text { Utilisation } \\
4.44 \% \\
\text { Total Parts } \\
40 \\
\text { Parts on Tim } \\
40\end{array}$ & $\begin{array}{l}\text { Build ID } \\
\text { M-0004-0 } \\
\text { Utilisation } \\
3.56 \% \\
\text { Total Parts } \\
34 \\
\text { Parts on Tin } \\
34\end{array}$ & $\begin{array}{l}\text { Build ID } \\
\text { M-0004-0 } \\
\text { Utilisation } \\
3.31 \% \\
\text { Total Parts } \\
4 \\
\text { Parts on Tin } \\
4\end{array}$ & $\begin{array}{l}\text { Build ID } \\
\text { M- } 0004-0 \\
\text { Utilisation } \\
3.31 \% \\
\text { Total Parts } \\
4 \\
\text { Parts on Tin } \\
4\end{array}$ \\
\hline
\end{tabular}




\section{Appendix D: Details of the LS AM build cost calculations}

Tables 10 to 17 present the total cost breakdown for each experiment.

The inventory carrying cost is assumed to be $5 \$$ per part per year. Moreover, for the bulk production mode, half an hour of production planning and control functions is assumed to be required. Moreover, to entirely avoid the inventory storage in kitting Experiments (3, 4, 7 and 8), we assumed the products are delivered to customers as soon as the assembly operations are completed. This assumption resulted in early delivery in kitting Experiments and in Experiments 3, 7 and 8 resulted in one additional customer delivery transportation. The cost of each delivery transportation is assumed to be $\$ 5$.

Table 10: Total cost breakdown for Experiment 1

\begin{tabular}{|c|c|c|c|}
\hline \multicolumn{4}{|c|}{ Experiment 1} \\
\hline Period & 1 & 2 & 3 \\
\hline Z-height (mm) & 328 & 314 & 236 \\
\hline Volume $\left(\mathrm{mm}^{3}\right)$ & 1345690.5 & 2190926.22 & 1010677.07 \\
\hline Cost of parts production $(\$)$ & $\$ 162.8$ & $\$ 187.6$ & $\$ 123.28$ \\
\hline Labour cost for loading the packed design into the machine & $\$ 12.5$ & $\$ 12.5$ & $\$ 12.5$ \\
\hline Labour cost of loading the file into 3DPackRAT & & $\$ 1.5$ & \\
\hline Total build cost (\$) & & $\$ 512.7$ & \\
\hline Inventory carrying cost & & $\$ 3.4$ & \\
\hline Costs related to production planning and control functions & & $\$ 12.5$ & \\
\hline Part sorting cost & & $\$ 12.6$ & \\
\hline Part fetching to feed the assembly & & $\$ 6.8$ & \\
\hline Transportation cost & & $\$ 40$ & \\
\hline Total cost & & $\$ 588$ & \\
\hline
\end{tabular}

Table 11: Total cost breakdown for Experiment 2

Experiment 2

\begin{tabular}{|c|c|c|c|}
\hline Period & 1 & 2 & 3 \\
\hline Z-height (mm) & 326 & 308 & 252 \\
\hline Volume $\left(\mathrm{mm}^{3}\right)$ & 1739336.13 & 1151967.23 & 1655989.81 \\
\hline Cost of parts production $(\$)$ & $\$ 175.73$ & $\$ 150.06$ & $\$ 150.33$ \\
\hline Labour cost for loading the packed design into the machine & $\$ 12.5$ & $\$ 12.5$ & $\$ 12.5$ \\
\hline Labour cost of loading the file into 3DPackRAT & & $\$ 1.5$ & \\
\hline Total build cost (\$) & & $\$ 515.1$ & \\
\hline Inventory carrying cost & & $\$ 3.9$ & \\
\hline Costs related to production planning and control functions & & $\$ 12.5$ & \\
\hline Part sorting cost & & $\$ 12.6$ & \\
\hline Part fetching to feed the assembly & & $\$ 6.8$ & \\
\hline Transportation cost & & $\$ 40$ & \\
\hline Total cost & & $\$ 590.9$ & \\
\hline
\end{tabular}

Table 12: Total cost breakdown for Experiment 3

Experiment 3

\begin{tabular}{lcccc}
\hline Period & 1 & 2 & 3 & 4 \\
\hline Z-height $(\mathrm{mm})$ & 312 & 298 & 295 & 147 \\
\hline & 1155543.6 & 1118676.5 & 1515138.4 & 757569.18 \\
Volume $\left(\mathrm{mm}^{3}\right)$ & 6 & 2 & 2 & 1 \\
\hline Cost of parts production $(\$)$ & $\$ 151.40$ & $\$ 145.87$ & $\$ 158.58$ & $\$ 87.48$
\end{tabular}


Labour cost for loading the packed design into the machine

\begin{tabular}{cc}
\hline Labour cost of kit design preparation in 3DPackRAT & $\$ 1.1$ \\
\hline Labour cost of loading the kits into 3DPackRAT & $\$ 0.1$ \\
\hline Transportation cost & $\$ 45$ \\
\hline Total cost (\$) & $\$ 639.5$ \\
\hline
\end{tabular}

Table 13: Total cost breakdown for Experiment 4

\begin{tabular}{|c|c|c|c|c|}
\hline \multicolumn{5}{|c|}{ Experiment 4} \\
\hline Period & 1 & 2 & 3 & 4 \\
\hline Z-height (mm) & 300 & 300 & 325 & 295 \\
\hline Volume $\left(\mathrm{mm}^{3}\right)$ & 722214.574 & 722214.574 & 1587359.71 & 1515138.42 \\
\hline Cost of parts production $(\$)$ & $\$ 132.85$ & $\$ 132.85$ & $\$ 170.20$ & $\$ 158.58$ \\
\hline $\begin{array}{l}\text { Labour cost for loading the packed design into the } \\
\text { machine }\end{array}$ & $\$ 12.5$ & $\$ 12.5$ & $\$ 12.5$ & $\$ 12.5$ \\
\hline Labour cost of kit design preparation in 3DPackRAT & \multicolumn{4}{|c|}{$\$ 1.1$} \\
\hline Labour cost of loading the kits into 3DPackRAT & \multicolumn{4}{|c|}{$\$ 0.1$} \\
\hline Transportation cost & \multicolumn{4}{|c|}{$\$ 40$} \\
\hline Total cost (\$) & \multicolumn{4}{|c|}{$\$ 685.6$} \\
\hline
\end{tabular}

Table 14: Total cost breakdown for Experiment 5

\begin{tabular}{|c|c|c|c|c|c|}
\hline \multicolumn{6}{|c|}{ Experiment 5} \\
\hline Period & 1 & 2 & 3 & 4 & 5 \\
\hline Z-height (mm) & 217 & 221 & 225 & 156 & 156 \\
\hline Volume $\left(\mathrm{mm}^{3}\right)$ & 1208399.6 & 829720.345 & 1422994.23 & 490904.481 & $\begin{array}{c}595275.22 \\
2 \\
\end{array}$ \\
\hline Cost of parts production $(\$)$ & $\$ 124.29$ & $\$ 112.49$ & $\$ 134.11$ & $\$ 81.06$ & $\$ 84.64$ \\
\hline $\begin{array}{l}\text { Labour cost for loading the packed design into the } \\
\text { machine }\end{array}$ & $\$ 12.5$ & $\$ 12.5$ & $\$ 12.5$ & $\$ 12.5$ & $\$ 12.5$ \\
\hline Labour cost of loading the file into 3DPackRAT & & & $\$ 6$ & & \\
\hline Total build cost (\$) & & & $\$ 605.1$ & & \\
\hline Inventory carrying cost & & & $\$ 0.9$ & & \\
\hline $\begin{array}{l}\text { Costs related to production planning and control } \\
\text { functions }\end{array}$ & & & $\$ 12.5$ & & \\
\hline Part sorting cost & & & $\$ 12.6$ & & \\
\hline Part fetching to feed the assembly & & & $\$ 6.8$ & & \\
\hline Transportation cost & & & $\$ 40$ & & \\
\hline Total cost & & & $\$ 677.8$ & & \\
\hline
\end{tabular}

Table 15: Total cost breakdown for Experiment 6

\begin{tabular}{lcccccc}
\hline \multicolumn{7}{c}{ Experiment 6} \\
1 & 2 & 3 & 4 & 5 \\
\hline Period & 229 & 235 & 218 & 209 & 110 \\
\hline Z-height $(\mathrm{mm})$ & 1129784.83 & 1143483.93 & 1172851.31 & 665055.367 & 436118.32
\end{tabular}




\begin{tabular}{|c|c|c|c|c|c|}
\hline Cost of parts production $(\$)$ & $\$ 125.24$ & $\$ 127.54$ & $\$ 123.37$ & $\$ 103.18$ & $\$ 65.17$ \\
\hline $\begin{array}{l}\text { Labour cost for loading the packed design into the } \\
\text { machine }\end{array}$ & $\$ 12.5$ & $\$ 12.5$ & $\$ 12.5$ & $\$ 12.5$ & $\$ 12.5$ \\
\hline Labour cost of loading the file into 3DPackRAT & & & $\$ 6$ & & \\
\hline Total build cost (\$) & & & $\$ 613$ & & \\
\hline Inventory carrying cost & & & $\$ 0.6$ & & \\
\hline $\begin{array}{l}\text { Costs related to production planning and control } \\
\text { functions }\end{array}$ & & & $\$ 12.5$ & & \\
\hline Part sorting cost & & & $\$ 12.6$ & & \\
\hline Part fetching to feed the assembly & & & $\$ 6.8$ & & \\
\hline Transportation cost & & & $\$ 40$ & & \\
\hline Total cost & & & $\$ 685.6$ & & \\
\hline
\end{tabular}

Table 16: Total cost breakdown for Experiment 7

\begin{tabular}{lccccc}
\hline \multicolumn{7}{c}{ Experiment 7 } & & & & \\
\hline Period & 1 & 2 & 3 & 4 & 5 \\
\hline Z-height $(\mathrm{mm})$ & 208 & 253 & 295 & 156 & 164 \\
\hline Volume $\left(\mathrm{mm}^{3}\right)$ & 902011.91 & 1028777.66 & 1515138.42 & 505550.028 & 595449.01 \\
\hline Cost of parts production (\$) & $\$ 111.02$ & $\$ 129.08$ & $\$ 158.58$ & $\$ 81.56$ & $\$ 87.09$ \\
\hline $\begin{array}{l}\text { Labour cost for loading the packed design into the } \\
\text { machine }\end{array}$ & $\$ 12.5$ & $\$ 12.5$ & $\$ 12.5$ & $\$ 12.5$ & $\$ 12.5$ \\
\hline Labour cost of kit design preparation in 3DPackRAT & & & $\$ 1.1$ & & \\
\hline Labour cost of loading the kits into 3DPackRAT & & $\$ 0.3$ & & \\
\hline Transportation cost & & $\$ 45$ & & \\
\hline Total cost (\$) & & $\$ 676.2$ & & \\
\hline
\end{tabular}

Table 17: Total cost breakdown for Experiment 8

\begin{tabular}{|c|c|c|c|c|c|}
\hline \multicolumn{6}{|c|}{ Experiment 8} \\
\hline Period & 1 & 2 & 3 & 4 & 5 \\
\hline Z-height (mm) & 311 & 240 & 295 & 210 & 163 \\
\hline Volume $\left(\mathrm{mm}^{3}\right)$ & 1353018.18 & 577771.539 & 1515138.42 & 505550.026 & 595448.70 \\
\hline Cost of parts production $(\$)$ & $\$ 157.88$ & $\$ 109.61$ & $\$ 158.58$ & $\$ 98.00$ & $\$ 86.78$ \\
\hline $\begin{array}{l}\text { Labour cost for loading the packed design into the } \\
\text { machine }\end{array}$ & $\$ 12.5$ & $\$ 12.5$ & $\$ 12.5$ & $\$ 12.5$ & $\$ 12.5$ \\
\hline Labour cost of kit design preparation in 3DPackRAT & & & $\$ 1.1$ & & \\
\hline Labour cost of loading the kits into 3DPackRAT & & & $\$ 0.3$ & & \\
\hline Transportation cost & & & $\$ 45$ & & \\
\hline Total cost (\$) & & & $\$ 719.7$ & & \\
\hline
\end{tabular}




\section{Appendix E: Order delivery performance cost analysis}

In the business-world timeliness regarding the order delivery is important. Not meeting a delivery schedule may have negative consequences ranging from direct contractual penalties to other costs such as lower customer service level and potentially lost sales. On the other hand, an early delivery may result in financial bonuses and higher customer satisfaction levels and customer loyalty.

In this Appendix, we present the actual product delivery tables for each experiment and compare them with the master delivery plan (Appendix A). The assumptions to calculate the supply chain impact of early or late delivery is that each late delivery has a penalty cost of $\$ 2$ per product per period while early delivery can save $\$ 1$ per product per period.

Table 18: Actual product delivery for Experiments 1 and 2

\begin{tabular}{r|c|c|c|c} 
& \multicolumn{2}{|c|}{ Experiment 1 } & \multicolumn{2}{c}{ Experiment 2 } \\
\hline & \multicolumn{2}{|c|}{ Actual delivery } & \multicolumn{2}{c}{ Actual delivery } \\
\hline Period (day) & Product A (drone) & $\begin{array}{l}\text { Product B (3D printer } \\
\text { extruder component) }\end{array}$ & Product A (drone) & $\begin{array}{l}\text { Product B (3D printer } \\
\text { extruder component) }\end{array}$ \\
\hline 1 & 0 & 0 & 0 & 0 \\
\hline 2 & 21 & 0 & 21 & 0 \\
\hline 3 & 0 & 8 & 0 & 8 \\
\hline 4 & 0 & 0 & 0 & 0 \\
\hline 5 & 0 & 0 & 0 & $\mathbf{8}$
\end{tabular}

Experiments 1 and 2 have similar product deliveries. In comparison to the delivery plan, the following costs and savings exist:

For the drone product, there is 1 missed delivery on first period, 7 early deliveries by 2 periods and 3 early deliveries by 3 periods. For FDM extruder product, there are two missed deliveries for 2 periods, 1 missed delivery for 1 period and 1 early delivery by 2 periods. In total, Experiments 1 and 2 provide $\$ 13$ of savings through early deliveries.

Table 19: Actual product delivery for Experiments 3 and 4

\begin{tabular}{r|c|c|c|c} 
& \multicolumn{2}{|c|}{ Experiment 3 } & \multicolumn{2}{c}{ Experiment 4 } \\
\hline & \multicolumn{2}{|c}{ Actual delivery } & \multicolumn{2}{c}{ Actual delivery } \\
\hline Period (day) & Product A (drone) & $\begin{array}{l}\text { Product B (3D printer } \\
\text { extruder component) }\end{array}$ & $\begin{array}{l}\text { Product A (drone) } \\
\text { extruct B (3D printer }\end{array}$ \\
\hline 1 & 16 & 0 & 10 & 0 \\
\hline 2 & 5 & 2 & 10 & 0 \\
\hline 3 & 0 & 4 & 1 & 4 \\
\hline 4 & 0 & 2 & 0 & 0 \\
\hline 5 & 0 & 0 & 0 & $\mathbf{8}$
\end{tabular}

In total, Experiments 3 and 4 respectively provide $\$ 31$ and $\$ 16$ of savings through early deliveries. 
Table 20: Actual product delivery for Experiments 5 and 6

\begin{tabular}{r|c|c|c|c} 
& \multicolumn{2}{|c|}{ Experiment 5 } & \multicolumn{2}{c}{ Experiment 6 } \\
\hline & \multicolumn{2}{|c|}{ Actual delivery } & \multicolumn{2}{c}{ Actual delivery } \\
Period (day) & Product A (drone) & $\begin{array}{l}\text { Product B (3D printer } \\
\text { extruder component) }\end{array}$ & $\begin{array}{l}\text { Product B (3D printer } \\
\text { extruder component) }\end{array}$ \\
\hline 1 & 1 & 2 & 1 & 2 \\
\hline 2 & 10 & 1 & 0 & 1 \\
\hline 3 & 0 & 4 & 7 & 4 \\
\hline 5 & 7 & 0 & 3 & 0 \\
\hline Total & 3 & 1 & $\mathbf{2 1}$ & $\mathbf{8}$
\end{tabular}

Experiments 5 and 6 do not offer any costs or savings as the actual delivery matches the plan.

Table 21: Actual product delivery for Experiments 7 and 8

\begin{tabular}{r|c|c|c|c} 
& \multicolumn{2}{|c|}{ Experiment 7 } & \multicolumn{2}{c}{ Experiment 8 } \\
\hline & \multicolumn{2}{|c|}{ Actual delivery } & \multicolumn{2}{c}{ Actual delivery } \\
\hline Period (day) & Product A (drone) & $\begin{array}{l}\text { Product B (3D printer } \\
\text { extruder component) }\end{array}$ & $\begin{array}{l}\text { Product A (drone) } \\
\text { extruder component) }\end{array}$ \\
\hline 1 & 2 & 2 & 3 & 3 \\
\hline 2 & 9 & 1 & 8 & 0 \\
\hline 4 & 0 & 4 & 0 & 4 \\
\hline 5 & 7 & 0 & 7 & 0 \\
\hline Total & 3 & 1 & 3 & $\mathbf{8}$
\end{tabular}

Experiments 7 and 8 respectively provide $\$ 1$ and $\$ 3$ of savings through early deliveries. 